\title{
Profiles of Airborne Fungi in Buildings and Outdoor Environments in the United States
}

\author{
Brian G. Shelton, ${ }^{1 *}$ Kimberly H. Kirkland, ${ }^{1}$ W. Dana Flanders, ${ }^{2}$ \\ and George K. Morris ${ }^{1}$ \\ PathCon Laboratories, Norcross, Georgia 30092, ${ }^{1}$ and Department of Epidemiology, \\ Rollins School of Public Health, Emory University, Atlanta, Georgia 30322 2
}

Received 25 September 2001/Accepted 13 January 2002

\begin{abstract}
We examined 12,026 fungal air samples (9,619 indoor samples and 2,407 outdoor samples) from 1,717 buildings located across the United States; these samples were collected during indoor air quality investigations performed from 1996 to 1998 . For all buildings, both indoor and outdoor air samples were collected with an Andersen N6 sampler. The culturable airborne fungal concentrations in indoor air were lower than those in outdoor air. The fungal levels were highest in the fall and summer and lowest in the winter and spring. Geographically, the highest fungal levels were found in the Southwest, Far West, and Southeast. The most common culturable airborne fungi, both indoors and outdoors and in all seasons and regions, were Cladosporium, Penicillium, nonsporulating fungi, and Aspergillus. Stachybotrys chartarum was identified in the indoor air in $6 \%$ of the buildings studied and in the outdoor air of $1 \%$ of the buildings studied. This study provides industrial hygienists, allergists, and other public health practitioners with comparative information on common culturable airborne fungi in the United States. This is the largest study of airborne indoor and outdoor fungal species and concentrations conducted with a standardized protocol to date.
\end{abstract}

Increasingly, fungi in indoor air are being proposed as a cause of adverse health effects $(3,7,10,11,13,14,23)$. Exposure to fungi has been reported to cause several types of human health problems, primarily irritations, infections, allergies, and toxic effects, and it has been suggested that toxigenic fungi are the cause of additional adverse health effects $(7,9,10,13$, 14). A field guide published by the American Industrial Hygiene Association recommends that the presence of some toxigenic fungi requires urgent risk management decisions (8). To systematically evaluate the relationship between airborne fungi and adverse health effects, the fungal types and their relative frequencies in both indoor and outdoor air need to be known. Increased understanding of airborne fungal populations should enable better interpretation of fungal exposure found in building air quality investigations.

Information obtained from fungal air samples can assist in medical evaluations, determination of remediation procedures, and assessment of health hazards and can be useful in proactive indoor air quality monitoring. Qualitative and quantitative assessments of fungi in indoor air are valuable; however, there are limitations in interpreting results obtained with bioaerosol samples. For example, there currently are no government or industry standards that specify allowable or acceptable concentrations of indoor airborne fungi. Also, only limited information is available on fungal types and their prevalence in buildings $(2,12,15,16,17,18,19,21,22,24,25,26)$. Similarly, there is little published information comparing indoor and outdoor fungal populations or comparing fungal populations in different parts of the United States. Without such comparative data, it is difficult to determine the significance of the quantitative

* Corresponding author. Mailing address: PathCon Laboratories, 270 Scientific Drive, Suite 3, Norcross, GA 30092. Phone: (770) 4460540. Fax: (770) 446-0610. E-mail: bshelton@pathcon.com. and qualitative results obtained in any particular indoor air quality investigation.

Fungi usually enter a building through outdoor air intakes of the heating, ventilation, and air conditioning system, through doors and windows, and as contaminants on building materials and contents. If elevated moisture conditions exist for a sufficient time in a building, fungal growth and sporulation may occur. Outdoor air often is the dominant source of indoor fungi, so an understanding of the outdoor fungal populations in different seasons and in different regions necessarily underlies interpretation of the results of indoor fungal sampling. Although other descriptive studies of indoor and outdoor fungi have described culturable fungal counts determined by using volumetric samplers, these studies usually were limited in terms of the number of study buildings and/or in terms of seasonal or regional effects $(2,12,15,16,17,18,19,21,22,24$, 25, 26).

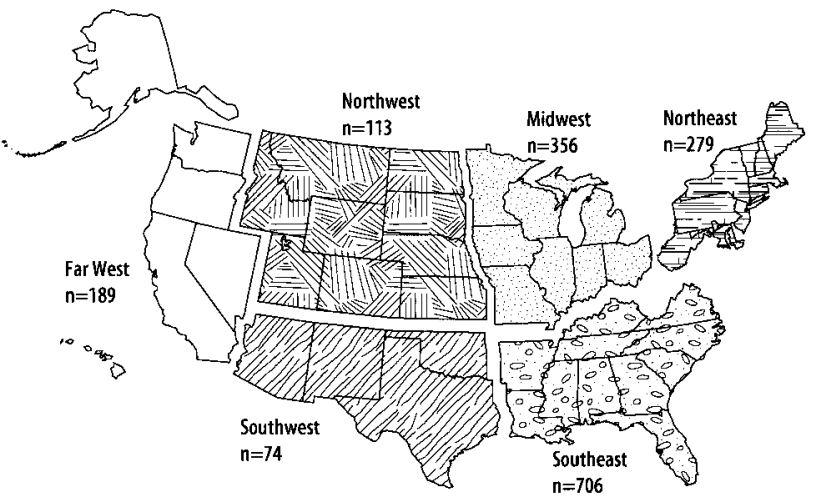

FIG. 1. Regions of the United States in which air samples were collected. n, number of buildings studied. 
TABLE 1. Median fungal concentrations and median indoor/outdoor fungal ratios

\begin{tabular}{|c|c|c|c|}
\hline \multirow[b]{2}{*}{ Parameter } & \multicolumn{2}{|c|}{ Concn $\left(\mathrm{CFU} / \mathrm{m}^{3}\right)^{a}$} & \multirow{2}{*}{$\begin{array}{l}\text { Indoor/outdoor ratio } \\
\text { for all buildings }{ }^{b} \\
\quad(n=1,717)\end{array}$} \\
\hline & $\begin{array}{c}\text { Outdoor } \\
(n=1,717)\end{array}$ & $\begin{array}{c}\text { Indoor } \\
(n=1,717)\end{array}$ & \\
\hline Minimum $(0 \%)$ & 1 & 1 & 0.00027 \\
\hline 25th percentile & 200 & 24 & 0.049 \\
\hline Median (50\%) & 540 & 82 & 0.16 \\
\hline 75th percentile & 1,200 & 240 & 0.45 \\
\hline 95th percentile & 3,200 & 1,300 & 2.8 \\
\hline Maximum $(100 \%)$ & $>8,200$ & $>10,000$ & 200 \\
\hline Mean & 930 & 300 & 1.1 \\
\hline
\end{tabular}

${ }^{a}$ The concentration was calculated by using the median fungal concentration for each building.

${ }^{b}$ The distribution of ratios for each building was calculated by dividing the median indoor building concentration by the corresponding median outdoor concentration.

The objectives of this study were (i) to describe the types and relative frequencies of both indoor and outdoor airborne fungi for three consecutive years by using samples obtained from different regions of the United States in different seasons of the year and (ii) to compare the species distributions and frequencies in indoor air and outdoor air. By using a standard- ized protocol for sample collection and analysis, we obtained essential comparative information that can be used by public health professionals as they interpret results of indoor air quality investigations.

\section{MATERIALS AND METHODS}

Air samples. All samples were submitted by building investigators as part of indoor air quality investigations in the United States from 1996 to 1998. These investigators included industrial hygienists, engineers, environmental health consultants, building managers, and safety personnel. A total of 12,026 samples, including 9,619 indoor samples and 2,407 outdoor samples, from 1,717 buildings were analyzed. At least one outdoor sample was collected for each building. The samples were collected with Andersen N6 samplers (Thermo Andersen, Inc., Atlanta, Ga.) using either Rose Bengal agar (RBA) or malt extract agar (MEA) as the culture medium. RBA (without streptomycin) was prepared using Martin's modification of peptone dextrose agar (20). MEA was prepared by using $25 \mathrm{~g}$ of malt extract per liter, $1 \mathrm{~g}$ of yeast extract per liter, and $16.5 \mathrm{~g}$ of agar per liter. RBA and MEA were used as the sampling media in approximately 99 and $1 \%$ of the buildings, respectively.

Questionnaire. We contacted building investigators for 100 randomly selected buildings from which samples were received in 1998 and asked them to complete a brief telephone questionnaire. The response rate for completed questionnaires was $82 \%$. From the responses we determined the type of building, the primary reason for performing the indoor air quality investigation, and the types of health complaints, if any. The building types included hospital, school, office building, residence, industrial, and other. The options for the primary reason for sampling were odors, health complaints, proactive sampling, visual growth, water damage,
Far West

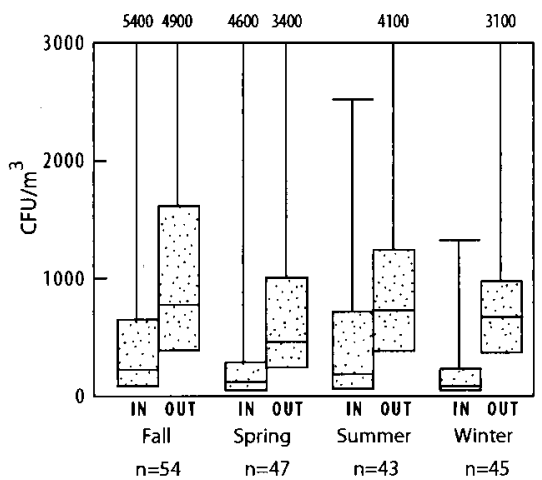

Northwest

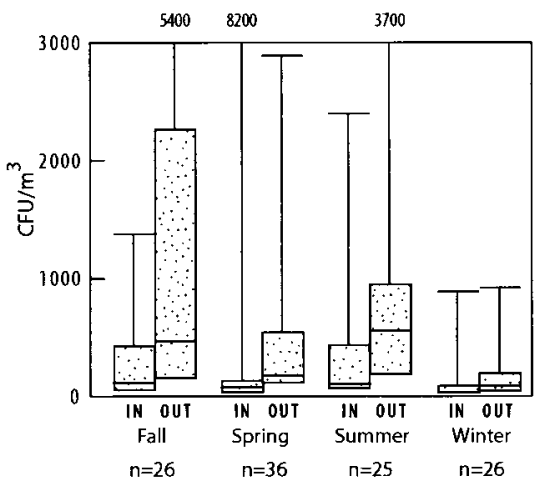

Midwest

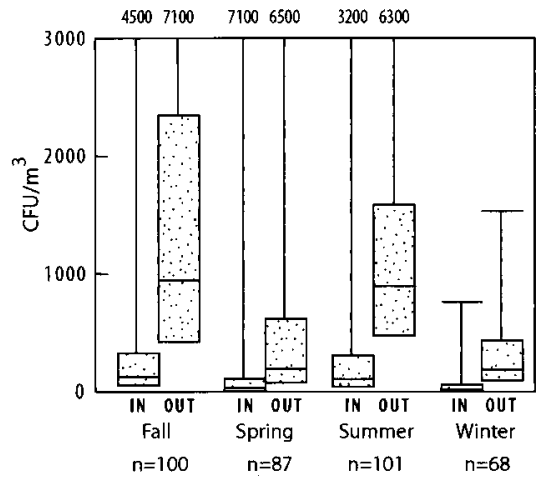

Southeast

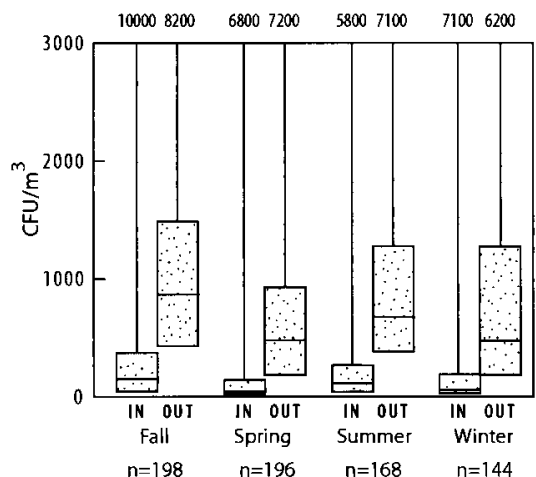

Northeast

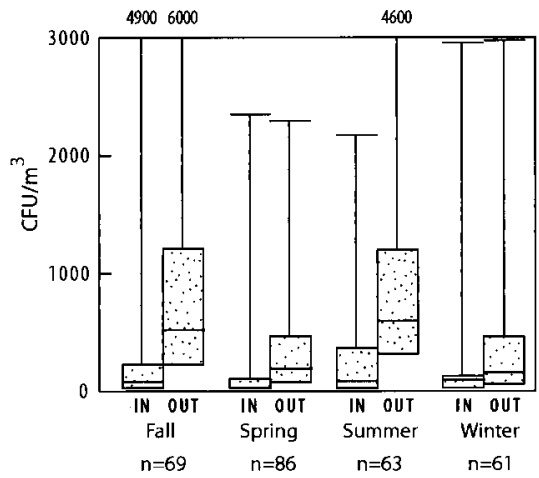

Southwest

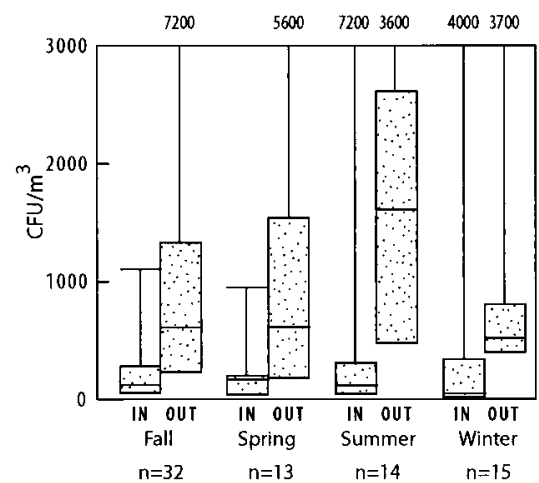

FIG. 2. Distribution of airborne fungal concentrations by region and season for indoor and outdoor samples. The dotted bars indicate the inner quartiles ranging from the 25th percentile to the 75 th percentile, and the horizontal lines indicate themedian fungal concentrations. The top of the vertical line represents the maximum observed value. The maximum value is shown at the top of the figure when it exceeds the scale. 
Far West

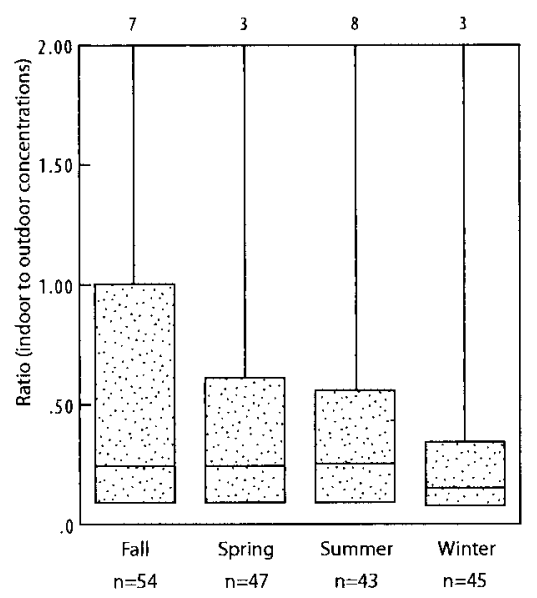

Northwest

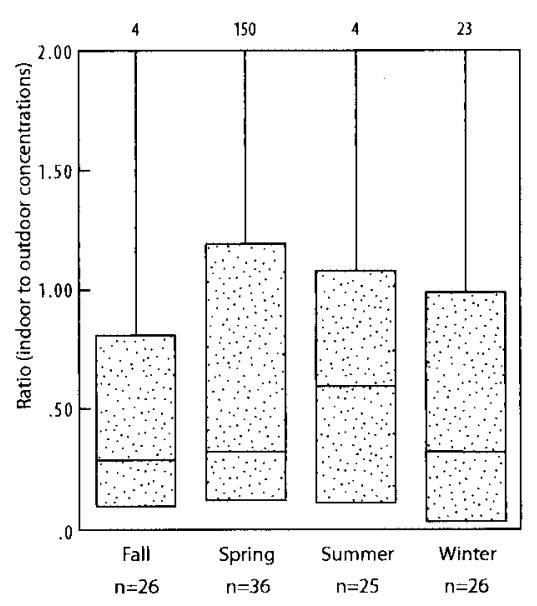

Midwest

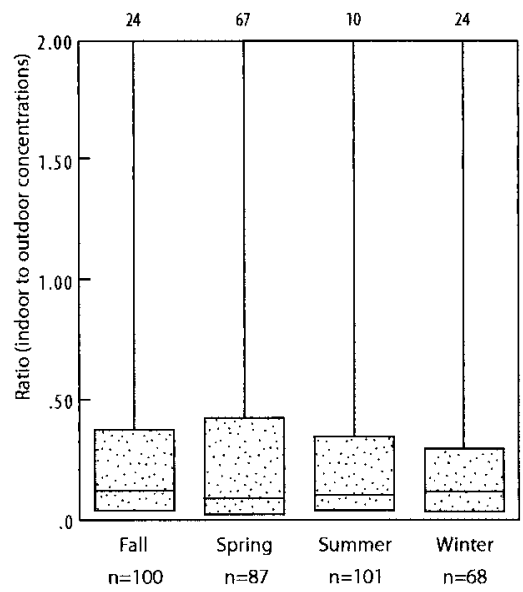

Southeast

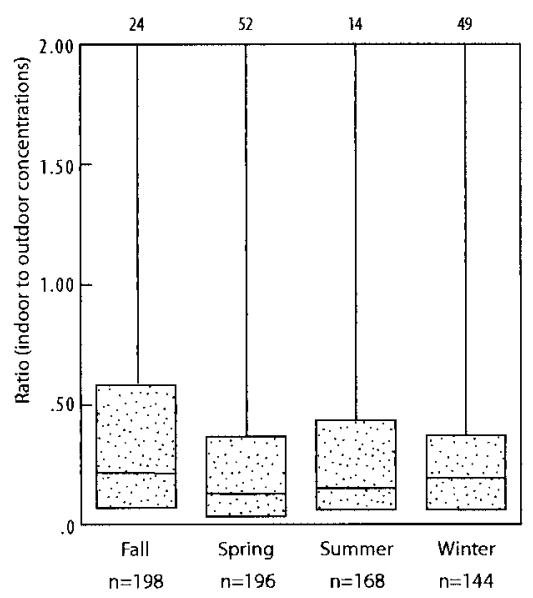

Northeast

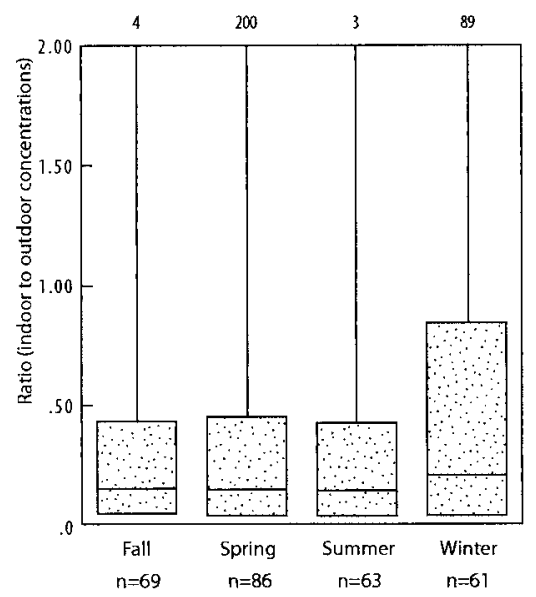

Southwest

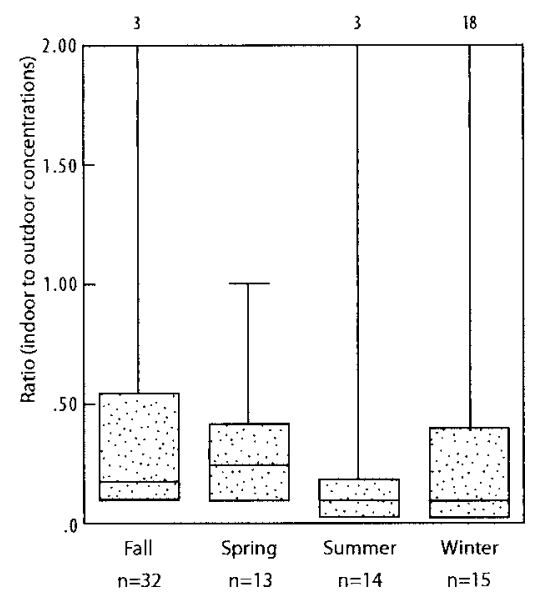

FIG. 3. Distribution of the indoor/outdoor fungal ratio for buildings by region and season. The dotted bars indicate the inner quartiles ranging from the 25 th percentile to the 75 th percentile, and the horizontal lines indicate the median fungal concentrations. The top of the vertical line represents the maximum observed value. The maximum value is shown at the top of the figure when it exceeds the scale.

and other, and multiple selections were possible. The options for health complaints, if indicated, were eye, throat, cough, shortness of breath, headache, skin, hypersensitivity pneumonitis, and other.

Sampling and analysis. We analyzed fungal air samples collected with Andersen N6 samplers, which are viable impaction samplers. Cultures were incubated in the laboratory at room temperature $\left(23 \pm 3^{\circ} \mathrm{C}\right)$. Plates were inspected after 4 days and periodically up to 14 days after primary exposure. The concentration of fungi per cubic meter of air was calculated, and the most common genera of fungi present were identified by macroscopic and/or microscopic analysis. Our analytical criterion was to identify the 10 most common fungal types if many types were present. However, for the vast majority of samples all fungal types present were identified. All fungal concentrations were expressed as CFU per cubic meter of air. Actual plate counts, not estimated counts, were used to calculate the CFU per cubic meter (1). The detection limit of the sampling procedure was typically $12 \mathrm{CFU} / \mathrm{m}^{3}$, but it occasionally varied depending on the volume of air collected during sampling. The concentrations for samples in which there was no growth (the concentrations were below the detection limits) were arbitrarily defined as $1 \mathrm{CFU} / \mathrm{m}^{3}$ for the purposes of analysis. Most fungi were identified to the genus level; the exceptions were Aspergillus and Stachybotrys isolates, which were identified to the species level. Fungi that failed to sporulate after 12 to 14 days were recorded as nonsporulating.

Fungal concentrations and statistical analysis. Indoor and outdoor samples for each building were analyzed separately using descriptive statistics, such as median, mean, and 25th, 75th, and 95th percentiles. Qualitative and quantitative results were compared by year, region, season, and indoor air versus outdoor air. Seasons were defined as winter (December, January, February), spring (March, April, May), summer (June, July, August), and fall (September, October, November). Regions were defined as Far West, Midwest, Northeast, Northwest, Southeast, and Southwest (Fig. 1). Analyses in which indoor air versus outdoor air, region, and season were examined were performed by using the percentages of samples positive for specific fungal types. The Kruskal-Wallis test was used to determine if there were statistically significant differences between yearly, seasonal, and regional fungal concentrations for both indoor air and outdoor air. To compare the presence of fungal type on the basis of reported reason for sample submission, we calculated odds ratios and Fisher exact two-tailed $P$ values. The odds ratios were calculated to compare the frequency of detection in buildings for which the stated reason for submission was health with the frequency of detection in buildings for which the stated reason for submission was proactive.

\section{RESULTS}

Overall concentrations. The median indoor fungal concentration was approximately $80 \mathrm{CFU} / \mathrm{m}^{3}$, and the values ranged from below the limit of detection to more than $10,000 \mathrm{CFU} / \mathrm{m}^{3}$ (Table 1). The median outdoor fungal concentration was ap- 
TABLE 2. Percentages of buildings positive for common fungal types by region and season

\begin{tabular}{|c|c|c|c|c|c|c|c|c|c|c|c|c|}
\hline \multirow{3}{*}{ Organism(s) } & \multicolumn{12}{|c|}{$\%$ of buildings positive } \\
\hline & \multicolumn{4}{|c|}{ Far West ${ }^{a}$} & \multicolumn{4}{|c|}{ Midwest } & \multicolumn{4}{|c|}{ Northeast } \\
\hline & $\begin{array}{c}\mathrm{F} \\
(n=54)^{b}\end{array}$ & $\begin{array}{c}\text { SP } \\
(n=47)\end{array}$ & $\begin{array}{c}\mathrm{SU} \\
(n=43)\end{array}$ & $\begin{array}{c}\mathrm{W} \\
(n=45)\end{array}$ & $\begin{array}{c}\mathrm{F} \\
(n=100)\end{array}$ & $\begin{array}{c}\mathrm{SP} \\
(n=87)\end{array}$ & $\begin{array}{c}\text { SU } \\
(n=101)\end{array}$ & $\begin{array}{c}\mathrm{W} \\
(n=68)\end{array}$ & $\begin{array}{c}\mathrm{F} \\
(n=69)\end{array}$ & $\begin{array}{c}\text { SP } \\
(n=86)\end{array}$ & $\begin{array}{c}\mathrm{SU} \\
(n=63)\end{array}$ & $\begin{array}{c}\mathrm{W} \\
(n=61)\end{array}$ \\
\hline Aspergillus flavus & $2 / 4^{d}$ & $0 / 0$ & $5 / 5$ & $0 / 0$ & $2 / 6$ & $5 / 1$ & $8 / 6$ & $3 / 4$ & $7 / 4$ & $0 / 0$ & $2 / 2$ & $2 / 5$ \\
\hline Aspergillus fumigatus & $35 / 29$ & $28 / 21$ & $42 / 30$ & $31 / 27$ & $26 / 30$ & $15 / 13$ & $32 / 35$ & $18 / 32$ & $38 / 30$ & $21 / 17$ & $23 / 27$ & $19 / 23$ \\
\hline Aspergillus niger & $31 / 44$ & $13 / 6$ & $30 / 37$ & $9 / 13$ & $23 / 29$ & $14 / 1$ & $32 / 28$ & $13 / 13$ & $25 / 28$ & $9 / 2$ & $13 / 21$ & $11 / 3$ \\
\hline Aspergillus species ${ }^{c}$ & $70 / 60$ & $64 / 36$ & $77 / 58$ & $62 / 44$ & $68 / 60$ & $57 / 37$ & $71 / 52$ & $52 / 60$ & $78 / 65$ & $55 / 30$ & $68 / 53$ & $65 / 44$ \\
\hline Aspergillus versicolor & $43 / 11$ & $34 / 9$ & $56 / 21$ & $33 / 4$ & $39 / 15$ & $36 / 3$ & $38 / 7$ & $33 / 16$ & $41 / 12$ & $24 / 9$ & $40 / 10$ & $44 / 18$ \\
\hline Acremonium & $11 / 2$ & $2 / 9$ & $5 / 5$ & $4 / 4$ & $14 / 4$ & $8 / 1$ & $15 / 4$ & $4 / 1$ & $10 / 6$ & $5 / 2$ & $11 / 3$ & $6 / 0$ \\
\hline Alternaria & $24 / 25$ & $15 / 15$ & $9 / 14$ & $9 / 13$ & $15 / 20$ & $9 / 13$ & $21 / 27$ & $10 / 10$ & $14 / 14$ & $1 / 6$ & $16 / 19$ & $8 / 5$ \\
\hline Aureobasidium & $17 / 9$ & $19 / 13$ & $5 / 9$ & $16 / 16$ & $14 / 7$ & $10 / 10$ & $7 / 8$ & $4 / 6$ & $17 / 30$ & $9 / 18$ & $10 / 18$ & $16 / 8$ \\
\hline Candida & $11 / 13$ & $19 / 15$ & $12 / 16$ & $24 / 24$ & $18 / 17$ & $7 / 20$ & $10 / 16$ & $10 / 7$ & $16 / 25$ & $9 / 13$ & $16 / 15$ & $3 / 11$ \\
\hline Cladosporium & $98 / 96$ & $94 / 98$ & $91 / 100$ & $87 / 96$ & $90 / 99$ & $67 / 84$ & $92 / 96$ & $70 / 79$ & $93 / 97$ & $72 / 79$ & $94 / 97$ & $71 / 59$ \\
\hline Curvularia & $2 / 2$ & $0 / 0$ & $0 / 2$ & $0 / 2$ & $2 / 2$ & $3 / 1$ & $2 / 2$ & $0 / 0$ & $7 / 1$ & $0 / 0$ & $8 / 3$ & $3 / 0$ \\
\hline Epicoccum & $19 / 7$ & $0 / 4$ & $2 / 14$ & $4 / 2$ & $18 / 27$ & $0 / 5$ & $13 / 16$ & $4 / 4$ & $14 / 16$ & $1 / 1$ & $11 / 15$ & $5 / 0$ \\
\hline Fusarium & $6 / 2$ & $21 / 2$ & $7 / 5$ & $2 / 7$ & $18 / 21$ & $5 / 2$ & $21 / 26$ & $0 / 6$ & $6 / 9$ & $0 / 3$ & $16 / 18$ & $16 / 0$ \\
\hline Geotrichum & $24 / 22$ & $36 / 30$ & $21 / 12$ & $36 / 62$ & $26 / 29$ & $23 / 36$ & $23 / 25$ & $24 / 49$ & $35 / 26$ & $29 / 37$ & $31 / 34$ & $21 / 41$ \\
\hline Hyalodendron & $17 / 0$ & $13 / 13$ & $12 / 9$ & $9 / 2$ & $4 / 0$ & $11 / 14$ & $8 / 5$ & $4 / 4$ & $4 / 4$ & $20 / 29$ & $21 / 6$ & $2 / 2$ \\
\hline Nonsporulating fungi & $81 / 93$ & $83 / 98$ & $86 / 95$ & $82 / 96$ & $84 / 95$ & $66 / 84$ & 91/98 & $70 / 85$ & $83 / 96$ & $64 / 85$ & $89 / 97$ & $76 / 80$ \\
\hline Penicillium & $91 / 82$ & $87 / 83$ & $86 / 88$ & 93/91 & $80 / 84$ & $64 / 59$ & $86 / 82$ & $64 / 60$ & $94 / 88$ & $71 / 55$ & $85 / 82$ & $71 / 56$ \\
\hline Rhinocladiella & $2 / 2$ & $2 / 2$ & $0 / 5$ & $0 / 2$ & $8 / 7$ & $3 / 0$ & $10 / 7$ & $0 / 0$ & $7 / 3$ & $3 / 0$ & $23 / 19$ & $0 / 0$ \\
\hline Rhodotorula & $41 / 38$ & $49 / 38$ & $26 / 42$ & $58 / 60$ & $35 / 41$ & $38 / 51$ & $36 / 27$ & $31 / 35$ & $49 / 48$ & $36 / 45$ & $35 / 26$ & $26 / 34$ \\
\hline S. chartarum & $15 / 2$ & $9 / 2$ & $5 / 0$ & $4 / 2$ & $8 / 0$ & $7 / 1$ & $8 / 2$ & $6 / 0$ & $10 / 0$ & $5 / 1$ & $3 / 2$ & $6 / 2$ \\
\hline Trichoderma & $7 / 4$ & $15 / 2$ & $7 / 2$ & $2 / 7$ & $13 / 16$ & $3 / 1$ & $12 / 5$ & $6 / 1$ & $10 / 4$ & $1 / 5$ & $5 / 5$ & $8 / 0$ \\
\hline Tritirachium & $24 / 9$ & $9 / 9$ & $9 / 14$ & $18 / 2$ & $56 / 37$ & $13 / 6$ & $30 / 22$ & $16 / 3$ & $48 / 39$ & $15 / 1$ & $32 / 15$ & $8 / 2$ \\
\hline Unidentified fungi & $4 / 0$ & $11 / 4$ & $9 / 9$ & $2 / 2$ & $8 / 2$ & $5 / 3$ & $4 / 1$ & $4 / 3$ & $10 / 3$ & $4 / 2$ & $10 / 3$ & $2 / 5$ \\
\hline Yeast & $20 / 13$ & $19 / 28$ & $21 / 19$ & $29 / 20$ & $19 / 12$ & $20 / 15$ & $35 / 17$ & $21 / 25$ & $35 / 20$ & $20 / 24$ & $35 / 10$ & $24 / 34$ \\
\hline
\end{tabular}

${ }^{a}$ See Fig. 1.

${ }^{b}$ F, fall; SP, spring; SU, summer; W, winter.

${ }^{c}$ Aspergillus species includes Eurotium, Emericella, A. flavus, A. fumigatus, A. niger, A. versicolor, and all other Aspergillus species listed in Table 3.

${ }^{d}$ Value for indoor samples/value for outdoor samples.

proximately $500 \mathrm{CFU} / \mathrm{m}^{3}$, and the range was similar. Ninetyfive percent of the buildings tested had a median indoor fungal concentration of less than $1,300 \mathrm{CFU} / \mathrm{m}^{3}$, and $95 \%$ had a median outdoor fungal concentration of less than 3,200 CFU/ $\mathrm{m}^{3}$. We calculated the ratio of the median indoor concentration for each building to the corresponding median outdoor concentration. The ratio was $1: 1$ or lower for $85 \%$ of the buildings, 2.8 or lower for $95 \%$ of the buildings, and 0.16 or lower for $50 \%$ of the buildings (Table 1). Indoor fungal concentrations (mean and median) correlated with the corresponding outdoor fungal concentrations with a Spearman correlation coefficient of $0.43(P<0.001)$.

Seasonal concentrations. Of the 1,717 buildings investigated, 359 were sampled in the winter, 465 were sampled in the spring, 414 were sampled in the summer, and 479 were sampled in the fall. The median outdoor fungal concentrations varied by season $(P=0.0001)$ and were highest in the fall and summer and lowest in the spring and winter. The indoor fungal concentrations varied in a similar manner $(P=0.0001)$. The ratio of indoor concentrations to outdoor concentrations did not vary substantially by season $(P=0.26)$.

Regional concentrations. The median outdoor fungal concentrations varied by region $(P=0.0001)$ and were highest in the Southwest, Far West, and Southeast and lowest in the Northwest (Fig. 2). The indoor fungal concentrations also varied by region $(P=0.0001)$ and, like the outdoor levels, were highest in the Southwest, Far West, and Southeast. The indoor concentrations were lowest in the Northeast. The ratio of in- door concentrations to outdoor concentrations varied significantly by region $(P=0.0001)$, and the highest ratios were in the Far West and the Northwest (Fig. 3).

Annual concentrations. Of the 1,717 buildings investigated, the numbers analyzed each year were 427 in 1996, 571 in 1997, and 719 in 1998 . Very small year-to-year variations occurred in the median outdoor concentrations $(P=0.19)$. No significant year-to-year variation was observed in the indoor fungal concentrations $(P=0.59)$ or in the ratio of indoor concentrations to outdoor concentrations $(P=0.48)$.

Fungi recovered. The fungi most commonly recovered from both indoor and outdoor air were Cladosporium, Penicillium, Aspergillus, and the nonsporulating fungi. For indoor samples, Cladosporium, Penicillium, the nonsporulating fungi, and $A s$ pergillus were detected in $86,80,80$, and $62 \%$ of the buildings, respectively. Cladosporium, Penicillium, the nonsporulating fungi, and Aspergillus were detected in 92, 77, 92, and $49 \%$ of the outdoor samples, respectively. These organisms were detected in all regions and in all seasons. When detected in indoor samples, Cladosporium was usually found at a median concentration of approximately $40 \mathrm{CFU} / \mathrm{m}^{3}$ (95\% confidence interval [CI], 12 to $480 \mathrm{CFU} / \mathrm{m}^{3}$ ); Penicillium was found at a median concentration of approximately $30 \mathrm{CFU} / \mathrm{m}^{3}(95 \% \mathrm{CI}$, 12 to $570 \mathrm{CFU} / \mathrm{m}^{3}$ ); Aspergillus was found at a median concentration of approximately $20 \mathrm{CFU} / \mathrm{m}^{3}$ (95\% CI, 12 to $373 \mathrm{CFU} /$ $\left.\mathrm{m}^{3}\right)$; and the nonsporulating fungi were found at a median concentration of approximately $30 \mathrm{CFU} / \mathrm{m}^{3}$ (95\% CI, 12 to 204 $\left.\mathrm{CFU} / \mathrm{m}^{3}\right)$. When detected in outdoor samples, Cladosporium 
TABLE 2-Continued

\begin{tabular}{|c|c|c|c|c|c|c|c|c|c|c|c|}
\hline \multicolumn{12}{|c|}{$\%$ of buildings positive } \\
\hline \multicolumn{4}{|c|}{ Northwest } & \multicolumn{4}{|c|}{ Southeast } & \multicolumn{4}{|c|}{ Southwest } \\
\hline $\begin{array}{c}\mathrm{F} \\
(n=26)\end{array}$ & $\begin{array}{c}\text { SP } \\
(n=36)\end{array}$ & $\begin{array}{c}\mathrm{SU} \\
(n=25)\end{array}$ & $\begin{array}{c}\mathrm{W} \\
(n=26)\end{array}$ & $\begin{array}{c}\mathrm{F} \\
(n=198)\end{array}$ & $\begin{array}{c}\text { SP } \\
(n=196)\end{array}$ & $\begin{array}{c}\mathrm{SU} \\
(n=168)\end{array}$ & $\begin{array}{c}\mathrm{W} \\
(n=144)\end{array}$ & $\begin{array}{c}\mathrm{F} \\
(n=32)\end{array}$ & $\begin{array}{c}\text { SP } \\
(n=13)\end{array}$ & $\begin{array}{c}\mathrm{SU} \\
(n=14)\end{array}$ & $\begin{array}{c}\mathrm{W} \\
(n=15)\end{array}$ \\
\hline $8 / 0$ & $0 / 3$ & $0 / 4$ & $0 / 4$ & $6 / 8$ & $5 / 2$ & $4 / 7$ & $4 / 1$ & $16 / 9$ & $0 / 0$ & $0 / 14$ & $0 / 0$ \\
\hline $23 / 19$ & $14 / 14$ & $24 / 32$ & $19 / 8$ & $21 / 20$ & $17 / 18$ & $17 / 18$ & $11 / 16$ & $13 / 3$ & $15 / 0$ & $14 / 14$ & $7 / 13$ \\
\hline $27 / 19$ & $14 / 8$ & $32 / 24$ & $19 / 12$ & $30 / 29$ & $10 / 7$ & $23 / 32$ & $14 / 9$ & $38 / 41$ & $8 / 8$ & $36 / 64$ & $13 / 27$ \\
\hline $69 / 35$ & $61 / 44$ & $64 / 48$ & $54 / 50$ & $73 / 56$ & $49 / 36$ & $57 / 52$ & $55 / 44$ & $72 / 53$ & $62 / 31$ & $50 / 79$ & $53 / 67$ \\
\hline $38 / 8$ & $31 / 8$ & $28 / 4$ & $19 / 19$ & $34 / 11$ & $28 / 6$ & $27 / 6$ & $26 / 12$ & $41 / 25$ & $38 / 0$ & $7 / 21$ & $33 / 27$ \\
\hline $15 / 12$ & $6 / 0$ & $4 / 0$ & $4 / 0$ & $11 / 12$ & $5 / 3$ & $6 / 4$ & $3 / 5$ & $28 / 13$ & $8 / 0$ & $0 / 0$ & $7 / 13$ \\
\hline $15 / 38$ & $11 / 14$ & $12 / 28$ & $15 / 19$ & $2 / 7$ & $5 / 9$ & $4 / 13$ & $4 / 6$ & $16 / 19$ & $0 / 15$ & $14 / 36$ & $0 / 20$ \\
\hline $8 / 8$ & $11 / 14$ & $8 / 4$ & $12 / 8$ & $9 / 11$ & $9 / 9$ & $10 / 7$ & $7 / 10$ & $13 / 25$ & $23 / 23$ & $14 / 7$ & $13 / 20$ \\
\hline $15 / 15$ & $8 / 6$ & $0 / 12$ & $8 / 4$ & $5 / 4$ & $8 / 8$ & $5 / 4$ & $5 / 9$ & $0 / 6$ & $31 / 8$ & $14 / 7$ & $7 / 13$ \\
\hline $85 / 92$ & $97 / 94$ & $88 / 96$ & $85 / 77$ & $89 / 96$ & $85 / 92$ & $86 / 96$ & $88 / 90$ & $88 / 91$ & $100 / 92$ & $86 / 100$ & $87 / 93$ \\
\hline $8 / 4$ & $0 / 0$ & $8 / 0$ & $0 / 0$ & $16 / 12$ & $4 / 3$ & $18 / 24$ & $5 / 6$ & $16 / 19$ & $0 / 0$ & $7 / 7$ & $0 / 13$ \\
\hline $19 / 15$ & $0 / 0$ & $12 / 8$ & $4 / 4$ & $5 / 9$ & $3 / 6$ & $5 / 10$ & $5 / 6$ & $3 / 6$ & $0 / 0$ & $7 / 0$ & $0 / 13$ \\
\hline $0 / 8$ & $3 / 3$ & $4 / 4$ & $4 / 4$ & $14 / 30$ & $7 / 9$ & $12 / 24$ & $1 / 15$ & $13 / 28$ & $8 / 8$ & $7 / 7$ & $0 / 0$ \\
\hline $12 / 8$ & $22 / 17$ & $28 / 24$ & $0 / 8$ & $21 / 30$ & $19 / 35$ & $24 / 32$ & $30 / 52$ & $16 / 6$ & $54 / 54$ & $29 / 43$ & $20 / 33$ \\
\hline $4 / 4$ & $8 / 0$ & $8 / 4$ & $8 / 0$ & $6 / 3$ & $15 / 17$ & $13 / 7$ & $8 / 3$ & $0 / 0$ & $8 / 31$ & $14 / 7$ & $7 / 0$ \\
\hline $77 / 88$ & $75 / 78$ & $88 / 92$ & $65 / 65$ & $85 / 94$ & $79 / 95$ & $83 / 100$ & $77 / 95$ & $75 / 81$ & $77 / 100$ & $71 / 93$ & $73 / 87$ \\
\hline $81 / 73$ & $75 / 47$ & $80 / 68$ & $73 / 50$ & $89 / 93$ & $70 / 72$ & $85 / 86$ & $75 / 74$ & $88 / 78$ & $62 / 69$ & 79/100 & $67 / 53$ \\
\hline $19 / 0$ & $6 / 0$ & $8 / 0$ & $0 / 0$ & $31 / 27$ & $10 / 10$ & $34 / 29$ & $10 / 10$ & $34 / 25$ & $15 / 23$ & $7 / 21$ & $13 / 7$ \\
\hline $39 / 46$ & $33 / 45$ & $32 / 20$ & $58 / 50$ & $29 / 27$ & $34 / 37$ & $27 / 21$ & $30 / 28$ & $28 / 16$ & $85 / 46$ & $29 / 29$ & $20 / 47$ \\
\hline $12 / 0$ & $8 / 3$ & $12 / 4$ & $0 / 0$ & $5 / 1$ & $4 / 2$ & $5 / 1$ & $1 / 0$ & $9 / 0$ & $8 / 0$ & $0 / 0$ & $27 / 0$ \\
\hline $4 / 0$ & $11 / 3$ & $4 / 4$ & $4 / 0$ & $9 / 8$ & $8 / 5$ & $9 / 8$ & $6 / 2$ & $6 / 3$ & $0 / 0$ & $14 / 14$ & $7 / 13$ \\
\hline $27 / 23$ & $14 / 3$ & $28 / 4$ & $12 / 0$ & $44 / 34$ & $20 / 11$ & $32 / 9$ & $21 / 20$ & $31 / 28$ & $15 / 8$ & $21 / 0$ & $20 / 7$ \\
\hline $0 / 8$ & $3 / 6$ & $12 / 16$ & $8 / 8$ & $15 / 4$ & $11 / 5$ & $7 / 2$ & $12 / 3$ & $19 / 6$ & $31 / 15$ & $14 / 0$ & $7 / 7$ \\
\hline $19 / 19$ & $58 / 33$ & $28 / 16$ & $46 / 31$ & $21 / 10$ & $27 / 11$ & $26 / 13$ & $24 / 17$ & $38 / 13$ & $38 / 15$ & $21 / 0$ & $27 / 0$ \\
\hline
\end{tabular}

was usually found at a median concentration of approximately $200 \mathrm{CFU} / \mathrm{m}^{3}$ (95\% CI, 18 to $1,849 \mathrm{CFU} / \mathrm{m}^{3}$ ); Penicillium was found at a median concentration of approximately $50 \mathrm{CFU} / \mathrm{m}^{3}$ (95\% CI, 12 to $377 \mathrm{CFU} / \mathrm{m}^{3}$ ); Aspergillus was found at a median concentration of approximately $20 \mathrm{CFU} / \mathrm{m}^{3}$ (95\% CI, 12 to $170 \mathrm{CFU} / \mathrm{m}^{3}$ ); and the nonsporulating fungi were found at a median concentration of approximately $100 \mathrm{CFU} / \mathrm{m}^{3}$ (95\% CI, 12 to $901 \mathrm{CFU} / \mathrm{m}^{3}$ ).

Samples also were analyzed by determining the percentages of buildings positive for specific fungal types found by region and season. The results for the most common fungal types found in different regions and in different seasons are shown in Table 2, and the results for the less common types are shown in Table 3. The concentrations (mean, median, and 95th percentile) of the common fungal types are shown for each region in Tables 4, 5, 6, 7, 8, and 9 and for each season in Tables 10, 11,12 , and 13.

Questionnaire results. Based on the telephone questionnaires, the building types were as follows: office building, $46 \%$; school, $18 \%$; hospital, $13 \%$; residence, $4 \%$; industrial, $0 \%$; and other, $18 \%$. The reasons for submitting samples fell into the following five categories: reported health complaints, $45 \%$; proactive sampling, $16 \%$; visible fungal growth, $8 \%$; water damage, $8 \%$; and other, $5 \%$. No difference was found between the fungal counts for the buildings whose investigators did participate in the telephone questionnaire (82\%) and the fungal counts for the buildings whose investigators did not participate in the telephone questionnaire $(18 \%)(P=0.09$ for median CFU per cubic meter and $P=0.26$ for mean CFU per cubic meter). The median indoor levels varied according to the primary reported reason for sample submission (Table 14).
The highest concentrations were found in samples submitted from buildings because of visible fungal growth. The next highest levels were found in samples from buildings for which there were health complaints. Total fungal counts were not associated with reported coughs $(P=0.8)$, reported skin problems $(P=0.5)$, or reported eye problems $(P=0.8)$. However, the median indoor levels were higher for buildings in which hypersensitivity pneumonitis was reported than for buildings with no reported hypersensitivity pneumonitis (260 and $47 \mathrm{CFU} / \mathrm{m}^{3}$, respectively; $P=0.02$ ).

Stachybotrys. The percentages of buildings positive for selected species sorted by reason for sample submission are shown in Table 15. Predominant species were chosen along with selected other fungi that have the potential to produce mycotoxins. Because of particular interest in toxigenic fungi, we noted that Stachybotrys chartarum was identified in indoor air in $6 \%$ of the buildings studied. When this species was present, the median concentration was $12 \mathrm{CFU} / \mathrm{m}^{3}$ (95\% CI, 12 to $118 \mathrm{CFU} / \mathrm{m}^{3}$ ). It was found in similar percentages of buildings in all regions and in all seasons. S. chartarum was identified in the outdoor air of $1 \%$ of the buildings studied. When it was detected, the median concentration was 12 $\mathrm{CFU} / \mathrm{m}^{3}$ (95\% CI, 4 to $318 \mathrm{CFU} / \mathrm{m}^{3}$ ). It also was found in outdoor air at similar frequencies in all regions and in all seasons.

Of the samples submitted primarily because of health complaints, 2 of 45 were positive for Stachybotrys (average median indoor concentration when the organism was present, $12 \mathrm{CFU} /$ $\mathrm{m}^{3}$ ). Of the samples submitted primarily because of visible fungal growth, three of eight were positive for Stachybotrys (average median indoor concentration when the organism was 


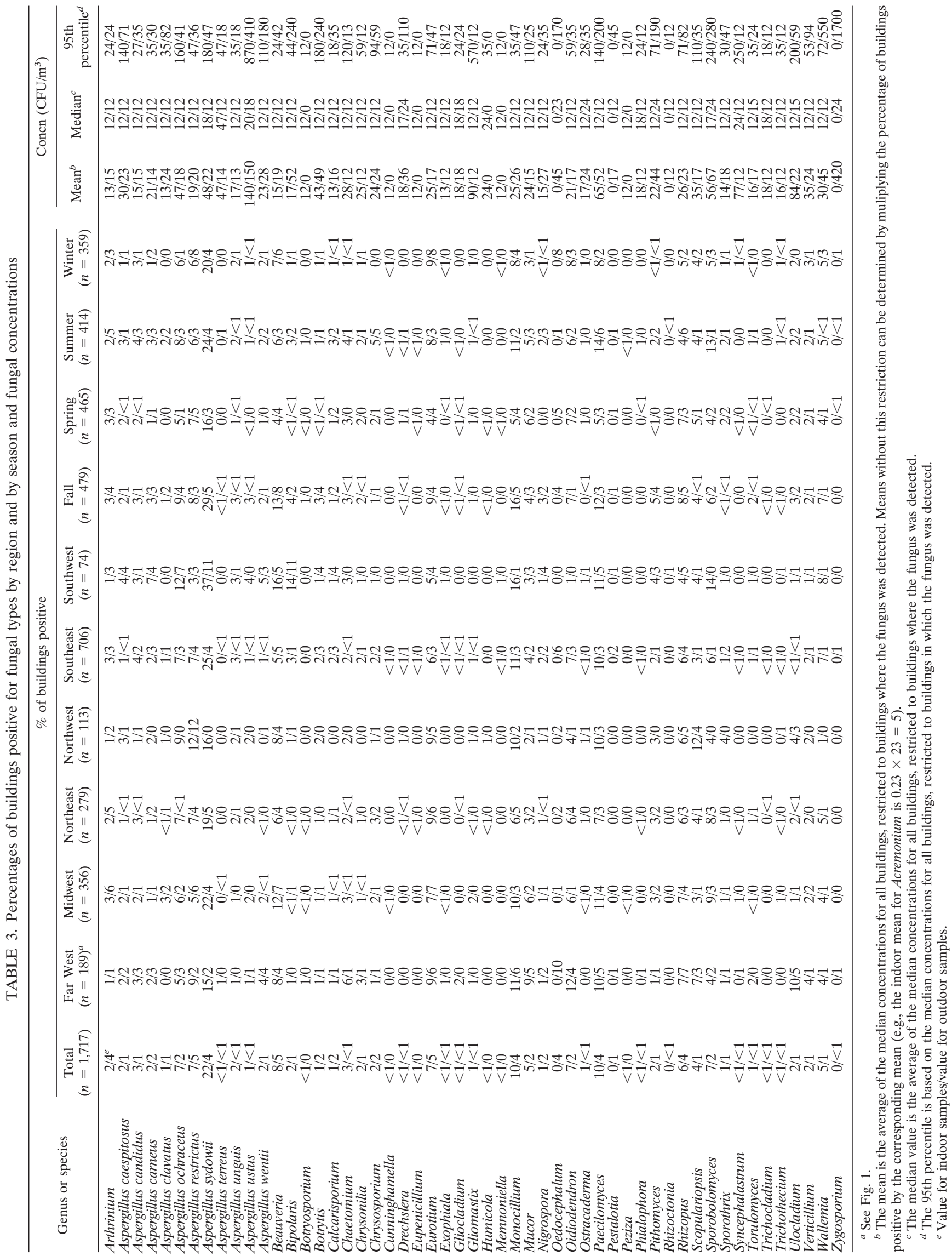


TABLE 4. Airborne fungal concentrations for the Far West

\begin{tabular}{lccc}
\hline \multirow{2}{*}{ Organism(s) } & \multicolumn{3}{c}{${\text { Concn }\left(\mathrm{CFU} / \mathrm{m}^{3}\right)}^{c}$} \\
\cline { 2 - 4 } & \multicolumn{1}{c}{ Mean $^{a}$} & Median $^{b}$ & 95 th percentilec $^{c}$ \\
\hline Aspergillus flavus & $32 / 15(24 / 6)^{e}$ & $24 / 12$ & $59 / 23$ \\
Aspergillus fumigatus & $22 / 69(27 / 230)$ & $12 / 18$ & $65 / 140$ \\
Aspergillus niger & $34 / 30(63 / 24)$ & $12 / 24$ & $200 / 82$ \\
Aspergillus species ${ }^{d}$ & $96 / 57(270 / 110)$ & $24 / 24$ & $420 / 180$ \\
Aspergillus versicolor & $120 / 17(300 / 12)$ & $13 / 12$ & $730 / 47$ \\
Acremonium & $25 / 27(38 / 26)$ & $12 / 12$ & $100 / 110$ \\
Alternaria & $20 / 32(13 / 27)$ & $12 / 24$ & $50 / 94$ \\
Aureobasidium & $32 / 20(97 / 10)$ & $12 / 12$ & $24 / 41$ \\
Candida & $19 / 24(18 / 22)$ & $12 / 24$ & $35 / 47$ \\
Cladosporium & $150 / 450(280 / 600)$ & $53 / 260$ & $790 / 1,800$ \\
Curvularia & $12 / 590(-/ 990)$ & $12 / 12$ & $12 / 1,700$ \\
Epicoccum & $19 / 15(9 / 5)$ & $18 / 12$ & $36 / 24$ \\
Fusarium & $15 / 16(5 / 7)$ & $12 / 12$ & $24 / 24$ \\
Geotrichum & $59 / 210(170 / 350)$ & $24 / 59$ & $190 / 950$ \\
Hyalodendron & $25 / 280(34 / 790)$ & $12 / 23$ & $47 / 2700$ \\
Nonsporulating fungi & $61 / 180(100 / 230)$ & $30 / 94$ & $190 / 520$ \\
Penicillium & $230 / 100(630 / 150)$ & $47 / 48$ & $1,300 / 380$ \\
Rhinocladiella & $28 / 21(5 / 21)$ & $28 / 12$ & $31 / 59$ \\
Rhodotorula & $20 / 53(14 / 100)$ & $12 / 24$ & $47 / 140$ \\
S. chartarum & $23 / 16(23 / 7)$ & $12 / 12$ & $110 / 24$ \\
Trichoderma & $15 / 12(7 / 0)$ & $12 / 12$ & $35 / 12$ \\
Tritirachium & $140 / 38(650 / 50)$ & $12 / 12$ & $59 / 190$ \\
Unidentified fungi & $17 / 14(6 / 5)$ & $12 / 12$ & $27 / 24$ \\
Yeast & $22 / 130(26 / 570)$ & $12 / 24$ & $58 / 180$ \\
\hline
\end{tabular}

${ }^{a}$ The mean is the average of the median concentrations for all buildings, restricted to buildings where the fungus was detected.

${ }^{b}$ The median value is the average of the median concentrations for all buildings, restricted to buildings where the fungus was detected.

${ }^{c}$ The 95 th percentile is based on the median concentrations for all buildings, restricted to buildings where the fungus was detected.

${ }^{d}$ Aspergillus species includes Eurotium, Emericella, A. flavus, A. fumigatus, $A$. niger, A. versicolor, and all other Aspergillus species listed in Table 3.

${ }^{e}$ Value for indoor samples/value for outdoor samples (standard deviation for indoor samples/standard deviation for outdoor samples).

TABLE 5. Airborne fungal concentrations for the Midwest

\begin{tabular}{|c|c|c|c|}
\hline \multirow{2}{*}{ Organism(s) } & \multicolumn{3}{|c|}{ Concn $\left(\mathrm{CFU} / \mathrm{m}^{3}\right)$} \\
\hline & $\operatorname{Mean}^{a}$ & $\operatorname{Median}^{b}$ & 95th percentile \\
\hline Aspergillus flavus & $78 / 30(240 / 46)^{e}$ & $12 / 15$ & $980 / 200$ \\
\hline Aspergillus fumigatus & $96 / 74(270 / 180)$ & $12 / 18$ & $650 / 380$ \\
\hline Aspergillus niger & $23 / 45(21 / 130)$ & $12 / 12$ & $71 / 110$ \\
\hline Aspergillus species ${ }^{d}$ & $110 / 65(300 / 180)$ & $18 / 24$ & $560 / 200$ \\
\hline Aspergillus versicolor & $75 / 15(210 / 9)$ & $12 / 12$ & $330 / 35$ \\
\hline Acremonium & $22 / 62(21 / 120)$ & $12 / 24$ & $59 / 210$ \\
\hline Alternaria & $19 / 70(15 / 100)$ & $12 / 35$ & $59 / 290$ \\
\hline Aureobasidium & $13 / 21(4 / 19)$ & $12 / 12$ & $24 / 41$ \\
\hline Candida & $14 / 23(6 / 21)$ & $12 / 12$ & $24 / 71$ \\
\hline Cladosporium & $130 / 550(300 / 780)$ & $42 / 210$ & $480 / 2,400$ \\
\hline Curvularia & $15 / 14(9 / 5)$ & $12 / 12$ & $35 / 24$ \\
\hline Epicoccum & $22 / 71(20 / 210)$ & $12 / 24$ & $71 / 180$ \\
\hline Fusarium & $17 / 37(10 / 44)$ & $12 / 24$ & $35 / 94$ \\
\hline Geotrichum & $50 / 140(110 / 300)$ & $24 / 35$ & $190 / 580$ \\
\hline Hyalodendron & $26 / 240(44 / 780)$ & $12 / 18$ & $47 / 2,000$ \\
\hline Nonsporulating fungi & $66 / 230(150 / 400)$ & $29 / 110$ & $190 / 800$ \\
\hline Penicillium & $130 / 140(330 / 360)$ & $32 / 36$ & $520 / 640$ \\
\hline Rhinocladiella & $23 / 37(25 / 41)$ & $12 / 24$ & $59 / 170$ \\
\hline Rhodotorula & $24 / 97(54 / 300)$ & $12 / 24$ & $41 / 400$ \\
\hline S. chartarum & $37 / 120(46 / 170)$ & $12 / 24$ & $140 / 320$ \\
\hline Trichoderma & $18 / 16(15 / 7)$ & $12 / 12$ & $35 / 24$ \\
\hline Tritirachium & $59 / 150(140 / 230)$ & $22 / 56$ & $190 / 530$ \\
\hline Unidentified fungi & $14 / 47(5 / 72)$ & $12 / 24$ & $24 / 220$ \\
\hline Yeast & $23 / 65(49 / 240)$ & $12 / 18$ & $55 / 180$ \\
\hline
\end{tabular}

${ }^{a}$ The mean is the average of the median concentrations for all buildings, restricted to buildings where the fungus was detected.

${ }^{b}$ The median value is the average of the median concentrations for all buildings, restricted to buildings where the fungus was detected.

${ }^{c}$ The 95 th percentile is based on the median concentrations for all buildings, restricted to buildings where the fungus was detected.

${ }^{d}$ Aspergillus species includes Eurotium, Emericella, A. flavus, A fumigatus, A. niger, A. versicolor, and all other Aspergillus species listed in Table 3.

${ }^{e}$ Value for indoor samples/value for outdoor samples (standard deviation for indoor samples/standard deviation for outdoor samples).
TABLE 6. Airborne fungal concentrations for the Northeast

\begin{tabular}{|c|c|c|c|}
\hline \multirow{2}{*}{ Organism(s) } & \multicolumn{3}{|c|}{ Concn $\left(\mathrm{CFU} / \mathrm{m}^{3}\right)$} \\
\hline & $\operatorname{Mean}^{a}$ & Median $^{b}$ & 95 th percentile ${ }^{c}$ \\
\hline Aspergillus flavus & $14 / 16(6 / 6)^{e}$ & $12 / 12$ & $21 / 24$ \\
\hline Aspergillus fumigatus & $23 / 54(40 / 110)$ & $12 / 12$ & $59 / 300$ \\
\hline Aspergillus niger & $24 / 25(25 / 51)$ & $12 / 12$ & $96 / 59$ \\
\hline Aspergillus species ${ }^{d}$ & $58 / 41(180 / 67)$ & $17 / 18$ & $200 / 190$ \\
\hline Aspergillus versicolor & $59 / 19(170 / 15)$ & $12 / 12$ & $280 / 53$ \\
\hline Acremonium & $24 / 39(24 / 38)$ & $12 / 20$ & $71 / 130$ \\
\hline Alternaria & $18 / 30(14 / 17)$ & $12 / 24$ & $42 / 59$ \\
\hline Aureobasidium & $16 / 28(11 / 42)$ & $12 / 12$ & $47 / 82$ \\
\hline Candida & $18 / 24(23 / 25)$ & $12 / 12$ & $71 / 82$ \\
\hline Cladosporium & $80 / 290(180 / 480)$ & $24 / 140$ & $360 / 1,200$ \\
\hline Curvularia & $13 / 22(2 / 15)$ & $12 / 24$ & $18 / 35$ \\
\hline Epicoccum & $18 / 24(10 / 16)$ & $12 / 23$ & $35 / 59$ \\
\hline Fusarium & $22 / 28(22 / 19)$ & $12 / 24$ & $83 / 71$ \\
\hline Geotrichum & $29 / 160(43 / 300)$ & $12 / 43$ & $89 / 660$ \\
\hline Hyalodendron & $31 / 140(45 / 330)$ & $12 / 35$ & $170 / 870$ \\
\hline Nonsporulating fungi & $57 / 200(120 / 370)$ & $24 / 71$ & $200 / 880$ \\
\hline Penicillium & $130 / 88(350 / 200)$ & $30 / 36$ & $500 / 240$ \\
\hline Rhinocladiella & $18 / 38(8 / 28)$ & $12 / 30$ & $35 / 110$ \\
\hline Rhodotorula & $21 / 53(16 / 96)$ & $12 / 24$ & $56 / 140$ \\
\hline S. chartarum & $17 / 9(11 / 5)$ & $12 / 12$ & $47 / 12$ \\
\hline Trichoderma & $18 / 14(18 / 5)$ & $12 / 12$ & $81 / 24$ \\
\hline Tritirachium & $53 / 110(150 / 190)$ & $12 / 47$ & $170 / 540$ \\
\hline Unidentified fungi & $13 / 19(6 / 8)$ & $12 / 12$ & $36 / 35$ \\
\hline Yeast & $26 / 30(58 / 40)$ & $12 / 22$ & $59 / 82$ \\
\hline
\end{tabular}

${ }^{a}$ The mean is the average of the median concentrations for all buildings, restricted to buildings where the fungus was detected.

${ }^{b}$ The median value is the average of the median concentrations for all buildings, restricted to buildings where the fungus was detected.

${ }^{c}$ The 95 th percentile is based on the median concentrations for all buildings, restricted to buildings where the fungus was detected.

${ }^{d}$ Aspergillus species includes Eurotium, Emericella, A. flavus, A. fumigatus, $A$. niger, A. versicolor, and all other Aspergillus species listed in Table 3.

${ }^{e}$ Value for indoor samples/value for outdoor samples (standard deviation for indoor samples/standard deviation for outdoor samples).

TABLE 7. Airborne fungal concentrations for the Northwest

\begin{tabular}{|c|c|c|c|}
\hline \multirow{2}{*}{ Organism(s) } & \multicolumn{3}{|c|}{ Concn $\left(\mathrm{CFU} / \mathrm{m}^{3}\right)$} \\
\hline & $\operatorname{Mean}^{a}$ & Median $^{b}$ & 95 th percentile ${ }^{c}$ \\
\hline Aspergillus flavus & $14 / 24(2 / 20)^{e}$ & $14 / 12$ & $15 / 47$ \\
\hline Aspergillus fumigatus & $24 / 28(23 / 47)$ & $12 / 12$ & $71 / 130$ \\
\hline Aspergillus niger & $24 / 21(17 / 14)$ & $12 / 12$ & $59 / 53$ \\
\hline Aspergillus species ${ }^{d}$ & $75 / 46(160 / 80)$ & 24/19 & $330 / 200$ \\
\hline Aspergillus versicolor & $100 / 22(290 / 14)$ & $20 / 12$ & $410 / 47$ \\
\hline Acremonium & $20 / 65(17 / 100)$ & $12 / 24$ & $59 / 350$ \\
\hline Alternaria & $23 / 53(16 / 65)$ & $22 / 35$ & $71 / 190$ \\
\hline Aureobasidium & $15 / 19(7 / 13)$ & $12 / 12$ & $36 / 47$ \\
\hline Candida & $18 / 26(13 / 40)$ & $12 / 12$ & $47 / 140$ \\
\hline Cladosporium & $85 / 410(150 / 700)$ & $42 / 110$ & $380 / 1,900$ \\
\hline Curvularia & $12 / 23(0 /-)$ & $12 / 23$ & $12 / 23$ \\
\hline Epicoccum & $45 / 36(60 / 26)$ & $12 / 23$ & $160 / 71$ \\
\hline Fusarium & $12 / 17(0 / 10)$ & $12 / 12$ & $12 / 35$ \\
\hline Geotrichum & $18 / 150(9 / 400)$ & $12 / 24$ & $42 / 1,600$ \\
\hline Hyalodendron & $23 / 18(12 / 8)$ & $20 / 18$ & $47 / 24$ \\
\hline Nonsporulating fungi & $37 / 120(46 / 240)$ & $24 / 59$ & $120 / 350$ \\
\hline Penicillium & $200 / 82(460 / 220)$ & $36 / 24$ & $1,300 / 270$ \\
\hline Rhinocladiella & 13/ND (4/ND)f & $12 / \mathrm{ND}$ & 24/ND \\
\hline Rhodotorula & $37 / 49(40 / 88)$ & $21 / 24$ & $160 / 150$ \\
\hline S. chartarum & $48 / 12(56 / 0)$ & $12 / 12$ & $160 / 12$ \\
\hline Trichoderma & $30 / 29(15 / 8)$ & $30 / 29$ & $56 / 35$ \\
\hline Tritirachium & $60 / 59(190 / 75)$ & $12 / 30$ & $94 / 240$ \\
\hline Unidentified fungi & $18 / 39(9 / 73)$ & $15 / 12$ & $35 / 250$ \\
\hline Yeast & $19 / 28(14 / 18)$ & $12 / 24$ & $37 / 70$ \\
\hline
\end{tabular}

${ }^{a}$ The mean is the average of the median concentrations for all buildings, restricted to buildings where the fungus was detected.

${ }^{b}$ The median value is the average of the median concentrations for all buildings, restricted to buildings where the fungus was detected.

${ }^{c}$ The 95 th percentile is based on the median concentrations for all buildings, restricted to buildings where the fungus was detected.

${ }^{d}$ Aspergillus species includes Eurotium, Emericella, A. flavus, A. fumigatus, $A$. niger, A. versicolor, and all other Aspergillus species listed in Table 3.

${ }^{e}$ Value for indoor samples/value for outdoor samples (standard deviation for indoor samples/standard deviation for outdoor samples)

${ }^{f} \mathrm{ND}$, not detected. 
TABLE 8. Airborne fungal concentrations for the Southeast

\begin{tabular}{|c|c|c|c|}
\hline \multirow{2}{*}{ Organism(s) } & \multicolumn{3}{|c|}{ Concn $\left(\mathrm{CFU} / \mathrm{m}^{3}\right)$} \\
\hline & $\operatorname{Mean}^{a}$ & $\operatorname{Median}^{b}$ & 95 th percentile ${ }^{c}$ \\
\hline Aspergillus flavus & $23 / 15(23 / 7)^{e}$ & $12 / 12$ & $83 / 35$ \\
\hline Aspergillus fumigatus & $20 / 32(22 / 45)$ & $12 / 18$ & $53 / 110$ \\
\hline Aspergillus niger & $54 / 30(150 / 44)$ & $12 / 12$ & $230 / 94$ \\
\hline Aspergillus species ${ }^{d}$ & $110 / 38(400 / 57)$ & $21 / 24$ & $410 / 120$ \\
\hline Aspergillus versicolor & $71 / 25(170 / 43)$ & $18 / 12$ & $310 / 82$ \\
\hline Acremonium & $23 / 41(21 / 53)$ & $15 / 24$ & $62 / 120$ \\
\hline Alternaria & $20 / 33(12 / 34)$ & $12 / 24$ & $44 / 94$ \\
\hline Aureobasidium & $16 / 32(6 / 32)$ & $12 / 22$ & $28 / 110$ \\
\hline Candida & $14 / 19(7 / 14)$ & $12 / 12$ & $24 / 59$ \\
\hline Cladosporium & $130 / 460(330 / 610)$ & $47 / 230$ & $480 / 1,600$ \\
\hline Curvularia & $28 / 58(27 / 92)$ & $18 / 35$ & $94 / 180$ \\
\hline Epicoccum & $19 / 40(24 / 77)$ & $12 / 18$ & $53 / 140$ \\
\hline Fusarium & $21 / 36(24 / 47)$ & $12 / 24$ & $71 / 140$ \\
\hline Geotrichum & $76 / 260(200 / 520)$ & $24 / 59$ & $260 / 1,300$ \\
\hline Hyalodendron & $31 / 110(45 / 340)$ & $17 / 25$ & $110 / 470$ \\
\hline Nonsporulating fungi & $66 / 280(120 / 510)$ & $30 / 140$ & $240 / 1,100$ \\
\hline Penicillium & $120 / 120(360 / 270)$ & $30 / 53$ & $490 / 400$ \\
\hline Rhinocladiella & $21 / 42(16 / 46)$ & $18 / 32$ & $47 / 130$ \\
\hline Rhodotorula & $28 / 59(60 / 130)$ & $15 / 24$ & $58 / 180$ \\
\hline S. chartarum & $34 / 53(73 / 88)$ & $12 / 12$ & $140 / 230$ \\
\hline Trichoderma & $23 / 18(47 / 11)$ & $12 / 12$ & $45 / 35$ \\
\hline Tritirachium & $46 / 79(150 / 140)$ & $18 / 34$ & $140 / 270$ \\
\hline Unidentified fungi & $19 / 23(16 / 16)$ & $12 / 18$ & $41 / 59$ \\
\hline Yeast & $21 / 26(24 / 16)$ & $12 / 24$ & $53 / 59$ \\
\hline
\end{tabular}

${ }^{a}$ The mean is the average of the median concentrations for all buildings, restricted to buildings where the fungus was detected.

${ }^{b}$ The median value is the average of the median concentrations for all buildings, restricted to buildings where the fungus was detected.

${ }^{c}$ The 95 th percentile is based on the median concentrations for all buildings, restricted to buildings where the fungus was detected.

${ }^{d}$ Aspergillus species includes Eurotium, Emericella, A. flavus, A. fumigatus, A. niger, A. versicolor, and all other Aspergillus species listed in Table 3.

${ }^{e}$ Value for indoor samples/value for outdoor samples (standard deviation for indoor samples/standard deviation for outdoor samples).

TABLE 9. Airborne fungal concentrations for the Southwest

\begin{tabular}{lccc}
\hline \multirow{2}{*}{ Organism(s) } & \multicolumn{3}{c}{${\text { Concn }\left(\mathrm{CFU} / \mathrm{m}^{3}\right)}$} \\
\cline { 2 - 4 } & \multicolumn{1}{c}{ Mean $^{a}$} & Median $^{b}$ & 95 th percentile $^{c}$ \\
\hline Aspergillus flavus & $11 / 17(2 / 7)^{e}$ & $12 / 12$ & $12 / 24$ \\
Aspergillus fumigatus & $16 / 43(11 / 62)$ & $12 / 12$ & $44 / 150$ \\
Aspergillus niger & $73 / 61(230 / 81)$ & $16 / 35$ & $550 / 200$ \\
Aspergillus species ${ }^{d}$ & $99 / 61(370 / 73)$ & $24 / 36$ & $230 / 200$ \\
Aspergillus versicolor & $75 / 15(190 / 5)$ & $14 / 12$ & $260 / 24$ \\
Acremonium & $22 / 24(18 / 15)$ & $14 / 20$ & $60 / 53$ \\
Alternaria & $19 / 59(13 / 42)$ & $12 / 50$ & $47 / 130$ \\
Aureobasidium & $160 / 21(49 / 16)$ & $12 / 12$ & $1,600 / 71$ \\
Candida & $14 / 16(5 / 6)$ & $12 / 12$ & $24 / 24$ \\
Cladosporium & $134 / 630(280 / 880)$ & $47 / 280$ & $490 / 3,500$ \\
Curvularia & $15 / 32(5 / 24)$ & $12 / 24$ & $24 / 71$ \\
Epicoccum & $9 / 14(4 / 8)$ & $9 / 12$ & $12 / 24$ \\
Fusarium & $16 / 79(9 / 170)$ & $12 / 24$ & $35 / 590$ \\
Geotrichum & $34 / 160(30 / 190)$ & $20 / 83$ & $110 / 600$ \\
Hyalodendron & $18 / 52(7 / 36)$ & $18 / 47$ & $24 / 94$ \\
Nonsporulating fungi & $63 / 350(77 / 630)$ & $31 / 140$ & $290 / 1,400$ \\
Penicillium & $150 / 80(500 / 100)$ & $36 / 33$ & $370 / 350$ \\
Rhinocladiella & $25 / 38(15 / 31)$ & $24 / 24$ & $65 / 110$ \\
Rhodotorula & $18 / 46(10 / 49)$ & $12 / 24$ & $36 / 170$ \\
S. chartarum & $15 / \mathrm{ND}(10 / \mathrm{ND})^{f}$ & $12 / \mathrm{ND}$ & $35 / \mathrm{ND}$ \\
Trichoderma & $15 / 71(11 / 130)$ & $12 / 12$ & $35 / 310$ \\
Tritirachium & $28 / 56(29 / 85)$ & $12 / 35$ & $130 / 290$ \\
Unidentified fungi & $19 / 21(23 / 15)$ & $12 / 12$ & $94 / 47$ \\
Yeast & $24 / 53(37 / 61)$ & $12 / 24$ & $67 / 170$ \\
\hline
\end{tabular}

${ }^{a}$ The mean is the average of the median concentrations for all buildings, restricted to buildings where the fungus was detected.

${ }^{b}$ The median value is the average of the median concentrations for all buildings, restricted to buildings where the fungus was detected.

${ }^{c}$ The 95 th percentile is based on the median concentrations for all buildings, restricted to buildings where the fungus was detected.

${ }^{d}$ Aspergillus species includes Eurotium, Emericella, A. flavus, A. fumigatus, $A$. niger, A. versicolor, and all other Aspergillus species listed in Table 3.

${ }^{e}$ Value for indoor samples/value for outdoor samples (standard deviation for indoor samples/standard deviation for outdoor samples).

${ }^{f} \mathrm{ND}$, not detected.
TABLE 10. Airborne fungal concentrations for fall

\begin{tabular}{|c|c|c|c|}
\hline \multirow{2}{*}{ Organism(s) } & \multicolumn{3}{|c|}{ Concn $\left(\mathrm{CFU} / \mathrm{m}^{3}\right)$} \\
\hline & $\operatorname{Mean}^{a}$ & $\operatorname{Median}^{b}$ & 95th percentilec \\
\hline Aspergillus flavus & $15 / 16(5 / 6)^{e}$ & $12 / 12$ & $24 / 24$ \\
\hline Aspergillus fumigatus & $37 / 48(130 / 120)$ & $12 / 18$ & $71 / 150$ \\
\hline Aspergillus niger & $26 / 32(42 / 40)$ & $12 / 15$ & $82 / 110$ \\
\hline Aspergillus species ${ }^{d}$ & $102 / 49(380 / 95)$ & $24 / 24$ & $370 / 190$ \\
\hline Aspergillus versicolor & $76 / 19(180 / 21)$ & $12 / 12$ & $410 / 47$ \\
\hline Acremonium & $24 / 56(23 / 94)$ & $15 / 30$ & $59 / 190$ \\
\hline Alternaria & 23/66 (17/70) & $12 / 36$ & $59 / 240$ \\
\hline Aureobasidium & $24 / 30(66 / 42)$ & $12 / 17$ & $30 / 82$ \\
\hline Candida & $19 / 25(23 / 27)$ & $12 / 12$ & $71 / 82$ \\
\hline Cladosporium & $180 / 640(410 / 820)$ & $59 / 290$ & $810 / 2,500$ \\
\hline Curvularia & $25 / 59(26 / 100)$ & $12 / 24$ & $94 / 280$ \\
\hline Epicoccum & $24 / 60(27 / 180)$ & $18 / 24$ & $53 / 150$ \\
\hline Fusarium & $23 / 43(25 / 69)$ & $12 / 24$ & $71 / 140$ \\
\hline Geotrichum & $62 / 280(180 / 560)$ & $21 / 59$ & $250 / 1,300$ \\
\hline Hyalodendron & $31 / 22(59 / 20)$ & $12 / 12$ & $110 / 71$ \\
\hline Nonsporulating fungi & $72 / 240(140 / 320)$ & $35 / 140$ & $250 / 870$ \\
\hline Penicillium & $150 / 160(410 / 330)$ & $38 / 71$ & $620 / 440$ \\
\hline Rhinocladiella & $22 / 45(13 / 36)$ & $18 / 35$ & $47 / 130$ \\
\hline Rhodotorula & $32 / 100(69 / 290)$ & $18 / 35$ & $63 / 410$ \\
\hline S. chartarum & $33 / 24(62 / 12)$ & $12 / 24$ & $120 / 35$ \\
\hline Trichoderma & $27 / 15(55 / 6)$ & $12 / 12$ & $81 / 35$ \\
\hline Tritirachium & $67 / 110(260 / 190)$ & $18 / 47$ & $190 / 410$ \\
\hline Unidentified fungi & $21 / 24(21 / 17)$ & $12 / 18$ & $65 / 71$ \\
\hline Yeast & $24 / 31(30 / 27)$ & $12 / 24$ & $67 / 82$ \\
\hline
\end{tabular}

${ }^{a}$ The mean is the average of the median concentrations for all buildings, restricted to buildings where the fungus was detected.

${ }^{b}$ The median value is the average of the median concentrations for all buildings, restricted to buildings where the fungus was detected.

${ }^{c}$ The 95 th percentile is based on the median concentrations for all buildings, restricted to buildings where the fungus was detected.

${ }^{d}$ Aspergillus species includes Eurotium, Emericella, A. flavus, A. fumigatus, $A$. niger, A. versicolor, and all other Aspergillus species listed in Table 3.

${ }^{e}$ Value for indoor samples/value for outdoor samples (standard deviation for indoor samples/standard deviation for outdoor samples).

TABLE 11. Airborne fungal concentrations for spring

\begin{tabular}{|c|c|c|c|}
\hline \multirow{2}{*}{$\operatorname{Organism}(\mathrm{s})$} & \multicolumn{3}{|c|}{ Concn $\left(\mathrm{CFU} / \mathrm{m}^{3}\right)$} \\
\hline & $\operatorname{Mean}^{a}$ & Median $^{b}$ & 95th percentile ${ }^{c}$ \\
\hline Aspergillus flavus & $20 / 13(16 / 2)^{e}$ & $12 / 12$ & $71 / 18$ \\
\hline Aspergillus fumigatus & $39 / 38(160 / 80)$ & $12 / 12$ & $47 / 130$ \\
\hline Aspergillus niger & $58 / 29(200 / 62)$ & $12 / 12$ & $110 / 53$ \\
\hline Aspergillus species ${ }^{d}$ & $66 / 33(280 / 54)$ & $18 / 18$ & $220 / 120$ \\
\hline Aspergillus versicolor & $42 / 20(92 / 16)$ & $18 / 12$ & $150 / 53$ \\
\hline Acremonium & $19 / 28(21 / 27)$ & $12 / 12$ & $59 / 110$ \\
\hline Alternaria & $16 / 26(8 / 28)$ & $12 / 12$ & $35 / 71$ \\
\hline Aureobasidium & $15 / 26(8 / 25)$ & $12 / 12$ & $35 / 110$ \\
\hline Candida & $15 / 24(7 / 24)$ & $12 / 12$ & $35 / 71$ \\
\hline Cladosporium & $86 / 350(200 / 590)$ & $35 / 130$ & $320 / 1,500$ \\
\hline Curvularia & $22 / 120(17 / 210)$ & $12 / 30$ & $59 / 550$ \\
\hline Epicoccum & $16 / 40(10 / 78)$ & $12 / 18$ & $36 / 350$ \\
\hline Fusarium & $16 / 36(8 / 68)$ & $12 / 18$ & $35 / 88$ \\
\hline Geotrichum & $55 / 190(200 / 420)$ & $18 / 40$ & $200 / 800$ \\
\hline Hyalodendron & $39 / 200(50 / 550)$ & $18 / 36$ & $170 / 870$ \\
\hline Nonsporulating fungi & $54 / 230(110 / 540)$ & $24 / 82$ & $160 / 1,000$ \\
\hline Penicillium & $130 / 52(430 / 95)$ & $24 / 24$ & $480 / 180$ \\
\hline Rhinocladiella & $21 / 21(14 / 14)$ & $12 / 12$ & $48 / 47$ \\
\hline Rhodotorula & $21 / 44(18 / 63)$ & $12 / 24$ & $47 / 170$ \\
\hline S. chartarum & $31 / 45(44 / 83)$ & $12 / 12$ & $140 / 230$ \\
\hline Trichoderma & $17 / 19(10 / 15)$ & $12 / 12$ & $35 / 59$ \\
\hline Tritirachium & $31 / 27(70 / 38)$ & $12 / 12$ & $59 / 59$ \\
\hline Unidentified fungi & $16 / 26(7 / 46)$ & $12 / 12$ & $35 / 36$ \\
\hline Yeast & $21 / 29(20 / 30)$ & $12 / 18$ & $48 / 71$ \\
\hline
\end{tabular}

${ }^{a}$ The mean is the average of the median concentrations for all buildings, restricted to buildings where the fungus was detected.

${ }^{b}$ The median value is the average of the median concentrations for all buildings, restricted to buildings where the fungus was detected.

${ }^{c}$ The 95th percentile is based on the median concentrations for all buildings, restricted to buildings where the fungus was detected.

${ }^{d}$ Aspergillus species includes Eurotium, Emericella, A. flavus, A. fumigatus, A. niger, A. versicolor, and all other Aspergillus species listed in Table 3.

${ }^{e}$ Value for indoor samples/value for outdoor samples (standard deviation for indoor samples/standard deviation for outdoor samples). 
TABLE 12. Airborne fungal concentrations for summer

\begin{tabular}{|c|c|c|c|}
\hline \multirow{2}{*}{ Organism(s) } & \multicolumn{3}{|c|}{ Concn $\left(\mathrm{CFU} / \mathrm{m}^{3}\right)$} \\
\hline & $\operatorname{Mean}^{a}$ & Median $^{b}$ & 95th percentile \\
\hline Aspergillus flavus & $77 / 26(230 / 38)^{e}$ & $15 / 12$ & $980 / 47$ \\
\hline Aspergillus fumigatus & $49 / 73(160 / 210)$ & $12 / 12$ & $130 / 320$ \\
\hline Aspergillus niger & $44 / 43(95 / 110)$ & $12 / 18$ & $180 / 83$ \\
\hline Aspergillus species ${ }^{d}$ & $120 / 69(320 / 160)$ & $24 / 24$ & $590 / 260$ \\
\hline Aspergillus versicolor & $120 / 18(300 / 13)$ & $18 / 12$ & $730 / 55$ \\
\hline Acremonium & $24 / 38(25 / 51)$ & $16 / 24$ & $71 / 140$ \\
\hline Alternaria & $21 / 49(16 / 78)$ & $16 / 25$ & $59 / 150$ \\
\hline Aureobasidium & $61 / 23(280 / 15)$ & $12 / 12$ & $24 / 49$ \\
\hline Candida & $14 / 17(7 / 8)$ & $12 / 12$ & $35 / 24$ \\
\hline Cladosporium & $130 / 500(260 / 580)$ & $47 / 290$ & $540 / 1,700$ \\
\hline Curvularia & $25 / 77(25 / 250)$ & $17 / 35$ & $82 / 150$ \\
\hline Epicoccum & $19 / 35(25 / 69)$ & $12 / 17$ & $71 / 140$ \\
\hline Fusarium & $17 / 35(13 / 40)$ & $12 / 24$ & $35 / 94$ \\
\hline Geotrichum & $63 / 120(120 / 260)$ & $24 / 44$ & $250 / 520$ \\
\hline Hyalodendron & $18 / 88(16 / 340)$ & $12 / 21$ & $47 / 59$ \\
\hline Nonsporulating fungi & $76 / 270(150 / 440)$ & $35 / 130$ & $300 / 1,100$ \\
\hline Penicillium & $160 / 140(410 / 320)$ & $40 / 60$ & $790 / 500$ \\
\hline Rhinocladiella & $21 / 40(22 / 38)$ & $12 / 30$ & $47 / 130$ \\
\hline Rhodotorula & $21 / 65(20 / 150)$ & $12 / 24$ & $59 / 250$ \\
\hline S. chartarum & $34 / 73(42 / 140)$ & $12 / 12$ & $140 / 320$ \\
\hline Trichoderma & $17 / 29(9 / 58)$ & $12 / 12$ & $35 / 35$ \\
\hline Tritirachium & $63 / 120(220 / 190)$ & $20 / 47$ & $170 / 620$ \\
\hline Unidentified fungi & $17 / 37(7 / 62)$ & $12 / 18$ & $35 / 250$ \\
\hline Yeast & $25 / 140(62 / 520)$ & $12 / 24$ & $48 / 240$ \\
\hline
\end{tabular}

${ }^{a}$ The mean is the average of the median concentrations for all buildings, restricted to buildings where the fungus was detected.

${ }^{b}$ The median value is the average of the median concentrations for all buildings, restricted to buildings where the fungus was detected.

${ }^{c}$ The 95th percentile is based on the median concentrations for all buildings, restricted to buildings where the fungus was detected.

${ }^{d}$ Aspergillus species includes Eurotium, Emericella, A. flavus, A. fumigatus, $A$. niger, A. versicolor, and all other Aspergillus species listed in Table 3.

${ }^{e}$ Value for indoor samples/value for outdoor samples (standard deviation for indoor samples/standard deviation for outdoor samples).

present, $52 \mathrm{CFU} / \mathrm{m}^{3}$ ). Of the samples submitted primarily because of water damage, two of eight were positive for Stachybotrys (average median indoor concentration when the organism was present, $12 \mathrm{CFU} / \mathrm{m}^{3}$ ). Of the samples submitted primarily for proactive sampling, none of 16 was positive for Stachybotrys. Detection of Stachybotrys in buildings for which reported health complaints were the primary reason for submission was not significantly different from detection in proactive comparison buildings. No statistically significant association was observed between any common fungal type and reported health complaints (Table 15).

\section{DISCUSSION}

This study is unique because it described culturable fungi obtained from indoor air and outdoor air from a large sample including samples collected during all four seasons of the year in six regions of the United States for several years. Overall, the median indoor fungal concentrations were 6 to 7 times lower than the median outdoor fungal concentrations.

The sizes of the median indoor and outdoor fungal populations varied significantly by season. Both the indoor and outdoor populations were largest in the fall and summer and smallest in the spring and summer. The higher outdoor concentrations in the summer and fall may reflect higher temperatures and humidities and resulting increases in microbiologi-
TABLE 13. Airborne fungal concentrations for winter

\begin{tabular}{llcc}
\hline \multirow{2}{*}{ Organism(s) } & \multicolumn{3}{c}{ Concn $\left(\mathrm{CFU} / \mathrm{m}^{3}\right)$} \\
\cline { 2 - 4 } & \multicolumn{1}{c}{ Mean $^{a}$} & Median $^{b}$ & 95 th percentile $^{c}$ \\
\hline Aspergillus flavus & $30 / 17(41 / 8)^{e}$ & $12 / 12$ & $120 / 35$ \\
Aspergillus fumigatus & $22 / 43(29 / 67)$ & $12 / 12$ & $75 / 190$ \\
Aspergillus niger & $50 / 17(150 / 14)$ & $13 / 12$ & $100 / 71$ \\
Aspergillus species ${ }^{d}$ & $79 / 37(240 / 57)$ & $18 / 18$ & $280 / 150$ \\
Aspergillus versicolor & $81 / 23(220 / 42)$ & $12 / 12$ & $510 / 47$ \\
Acremonium & $22 / 28(24 / 30)$ & $12 / 12$ & $71 / 130$ \\
Alternaria & $14 / 31(8 / 32)$ & $12 / 13$ & $36 / 120$ \\
Aureobasidium & $16 / 26(8 / 26)$ & $12 / 12$ & $36 / 95$ \\
Candida & $14 / 21(6 / 20)$ & $12 / 12$ & $30 / 47$ \\
Cladosporium & $68 / 260(130 / 430)$ & $28 / 94$ & $230 / 1,100$ \\
Curvularia & $14 / 33(3 / 28)$ & $12 / 35$ & $18 / 110$ \\
Epicoccum & $20 / 22(24 / 16)$ & $12 / 12$ & $110 / 71$ \\
Fusarium & $17 / 22(10 / 18)$ & $12 / 18$ & $35 / 35$ \\
Geotrichum & $39 / 220(57 / 400)$ & $24 / 59$ & $140 / 1,200$ \\
Hyalodendron & $18 / 15(8 / 7)$ & $12 / 12$ & $35 / 24$ \\
Nonsporulating fungi & $39 / 210(53 / 420)$ & $24 / 83$ & $150 / 760$ \\
Penicillium & $120 / 72(380 / 150)$ & $24 / 35$ & $520 / 280$ \\
Rhinocladiella & $15 / 50(6 / 91)$ & $12 / 18$ & $35 / 390$ \\
Rhodotorula & $25 / 47(52 / 63)$ & $12 / 24$ & $56 / 170$ \\
S. chartarum & $14 / 8(6 / 6)$ & $12 / 8$ & $35 / 12$ \\
Trichoderma & $16 / 15(9 / 8)$ & $12 / 12$ & $36 / 35$ \\
Tritirachium & $38 / 57(120 / 90)$ & $12 / 24$ & $47 / 200$ \\
Unidentified fungi & $14 / 18(5 / 11)$ & $12 / 12$ & $24 / 47$ \\
Yeast & $19 / 24(16 / 16)$ & $12 / 18$ & $59 / 59$ \\
& &
\end{tabular}

${ }^{a}$ The mean is the average of the median concentrations for all buildings, restricted to buildings where the fungus was detected.

${ }^{b}$ The median value is the average of the median concentrations for all buildings, restricted to buildings where the fungus was detected.

${ }^{c}$ The 95 th percentile is based on the median concentrations for all buildings, restricted to buildings where the fungus was detected.

${ }^{d}$ Aspergillus species includes Eurotium, Emericella, A. flavus, A. fumigatus, A. niger, A. versicolor, and all other Aspergillus species listed in Table 3.

${ }^{e}$ Value for indoor samples/value for outdoor samples (standard deviation for indoor samples/standard deviation for outdoor samples).

cal activity in these periods. The ratio of the concentration of fungi in indoor air to the concentration of fungi in outdoor air remained fairly constant in all seasons, even though the absolute levels fluctuated. This observation is consistent with the hypothesis that outdoor air has an important influence on indoor air quality. Thus, outdoor comparison samples should be collected when indoor air quality investigations are conducted. Although the median fungal ratio remained fairly con-

TABLE 14. Fungal concentrations sorted by reason for sampling

\begin{tabular}{|c|c|c|c|c|}
\hline \multirow[b]{2}{*}{ Reason } & \multirow{2}{*}{$\begin{array}{l}\text { No. of } \\
\text { samples }\end{array}$} & \multicolumn{2}{|c|}{ Concn $\left(\mathrm{CFU} / \mathrm{m}^{3}\right)$} & \multirow{2}{*}{$\begin{array}{l}\text { Median indoor } \\
\text { outdoor ratio }\end{array}$} \\
\hline & & $\begin{array}{c}\text { Indoor } \\
\text { mean }\end{array}$ & $\begin{array}{l}\text { Indoor } \\
\text { median }\end{array}$ & \\
\hline Health $^{a}$ & 45 & 101 & 71 & 0.21 \\
\hline Visible fungi $^{b}$ & 8 & 379 & 141 & 0.29 \\
\hline Water damage ${ }^{c}$ & 8 & 56 & 46 & 0.12 \\
\hline Proactive & 16 & 31 & 12 & 0.02 \\
\hline
\end{tabular}

${ }^{a}$ The questionnaire responses for health included the following categories: eye, throat, cough, shortness of breath, headache, skin, hypersensitivity pneumonitis, and other. For purposes of analysis, health included health, odor and health, water damage and health, visual growth and health, odor and visual growth and health, and water damage and visual growth and health.

${ }^{b}$ For purposes of analysis, visible fungi included visual growth, and visual growth and water damage.

${ }^{c}$ For purposes of analysis, water damage included water damage and odor and water damage. 
TABLE 15. Percentages of buildings positive for common fungal species sorted by reason for submission and odds ratios for association with reported health effects

\begin{tabular}{|c|c|c|c|c|c|c|}
\hline \multirow[b]{2}{*}{ Organism(s) } & \multicolumn{4}{|c|}{$\%$ of buildings positive } & \multirow[b]{2}{*}{ Odds ratio $^{d}$} & \multirow[b]{2}{*}{$P$ value } \\
\hline & $\begin{array}{l}\text { Health } \\
(n=45)^{a}\end{array}$ & $\begin{array}{l}\text { Visible fungi } \\
\quad(n=8)^{b}\end{array}$ & $\begin{array}{l}\text { Water damage } \\
\quad(n=8)^{c}\end{array}$ & $\begin{array}{l}\text { Proactive } \\
(n=16)\end{array}$ & & \\
\hline Acremonium & 9 & 25 & 0 & 19 & 0.4 & 0.4 \\
\hline Aspergillus species ${ }^{f}$ & 71 & 83 & 75 & 69 & 1.1 & 1.0 \\
\hline Aspergillus flavus & 2 & 13 & 25 & 0 & Undefined $^{g}$ & 1.0 \\
\hline Aspergillus fumigatus & 20 & 38 & 25 & 31 & 0.6 & 0.5 \\
\hline Aspergillus niger & 22 & 38 & 25 & 19 & 1.2 & 1.0 \\
\hline Aspergillus versicolor & 40 & 63 & 38 & 25 & 2.0 & 0.4 \\
\hline Alternaria & 13 & 0 & 0 & 0 & Undefined & 0.3 \\
\hline Aureobasidium & 18 & 0 & 0 & 0 & Undefined & 0.1 \\
\hline Candida & 4 & 0 & 0 & 6 & 0.7 & 1.0 \\
\hline Cladosporium & 87 & 100 & 63 & 94 & 0.4 & 0.7 \\
\hline Curvularia & 22 & 13 & 0 & 6 & 4.3 & 0.3 \\
\hline Epicoccum & 7 & 0 & 0 & 13 & 0.5 & 0.6 \\
\hline Fusarium & 11 & 13 & 0 & 13 & 0.9 & 1.0 \\
\hline Geotrichum & 24 & 50 & 38 & 31 & 0.7 & 0.7 \\
\hline Hyalodendron & 16 & 0 & 13 & 19 & 0.8 & 0.7 \\
\hline Nonsporulating fungi & 80 & 100 & 50 & 69 & 1.8 & 0.5 \\
\hline Penicillium & 82 & 100 & 63 & 88 & 0.7 & 1.0 \\
\hline Rhinocladiella & 16 & 25 & 25 & 19 & 0.8 & 0.7 \\
\hline Rhodotorula & 36 & 38 & 25 & 31 & 1.2 & 1.0 \\
\hline Stachybotrys & 4 & 38 & 25 & 0 & Undefined & 1.0 \\
\hline Trichoderma & 11 & 13 & 13 & 13 & 0.9 & 1.0 \\
\hline Unidentified fungi & 7 & 0 & 0 & 0 & Undefined & 0.6 \\
\hline Yeast & 22 & 13 & 25 & 25 & 0.9 & 1.0 \\
\hline
\end{tabular}

${ }^{a}$ The questionnaire responses for health included the following categories: eye, throat, cough, shortness of breath, headache, skin, hypersensitivity pneumonitis, and other. For purposes of analysis, health included health, odor and health, water damage and health, visual growth and health, odor and visual growth and health, and water damage and visual growth and health.

${ }^{b}$ For purposes of analysis, visible fungi included visual growth and visual growth and water damage.

${ }^{c}$ For purposes of analysis, water damage included water damage and odor and water damage.

${ }^{d}$ The odds ratio measures the association between reporting of health effects and detection of fungal type in buildings using as the comparison category buildings for which proactive was reported as the reason for submission. For example, the odds ratio for Acremonium is $(0.09)(1-0.19) \div[(1-0.09) \times(0.19)]=0.4$.

${ }^{f}$ Aspergillus species includes Eurotium, Emericella, A. flavus, A. fumigatus, A. niger, A. versicolor, and all other Aspergillus species listed in Table 3.

${ }^{g}$ For undefined odds ratios the denominator is zero.

stant from season to season, there was substantial variation from building to building.

The regional variation in fungal concentrations was substantial, and the indoor and outdoor concentrations were highest in the Southwest, Far West, and Southeast. The outdoor levels were lowest in the Northwest, and the values were intermediate in the other two regions. The indoor concentrations were lowest in the Northeast and intermediate in the other two areas. The ratio of indoor fungal population size to outdoor fungal population size ranged from about 0.1 to about 0.5 . There was no significant variation in the seasonal ratios, so region may be more important than season in determining ratios of indoor population size to outdoor population size. The indoor and outdoor populations varied only slightly from year to year, and the variation was not statistically significant.

Cladosporium, Penicillium, Aspergillus, and nonsporulating fungi were the most common fungi indoors and outdoors in each season and in each region. The significance of the presence of $S$. chartarum in indoor settings is currently being debated $(4,5,6,8,10)$. $S$. chartarum was detected in the indoor air of $6 \%$ of the buildings sampled and in the outdoor air of $1 \%$ of the buildings sampled; however, we had four times as many indoor samples as outdoor samples. The results of this study suggest that the presence of Stachybotrys is not highly unusual and that this genus is present at similar frequencies across the United States.
Fungal analyses were requested for different reasons, including employee health complaints, assessment of microbial levels following water damage, evaluation of visible fungal growth or odors, or as part of a proactive indoor air quality program. The median indoor fungal levels varied according to the primary reason for sample submission; buildings for which visible fungal growth was reported had the largest populations, proactive samples had the smallest populations, and the populations in buildings in which there was water damage or health complaints were intermediate. We found particularly large fungal populations in association with reported hypersensitivity pneumonitis, which presumably reflected the known causal connection between hypersensitivity pneumonitis and exposure to high fungal levels (27). Although the purpose of this study was not to measure any potential health association and the number of questionnaires was small, we found no association between reported health complaints and the presence of any common fungal type or potentially toxigenic fungus.

The submitted samples which we analyzed were not collected randomly, but they did indicate the range of fungal concentrations and the most common airborne fungi in buildings across the United States. The other limitations of our data set include (i) the fact there was no information about the reason for sample collection (for samples other than the subset of samples for which questionnaire information was received), (ii) the fact that there was no information about the building 
conditions where samples were collected, and (iii) the fact that there was no information about whether samples were taken from complaint areas. However, results for outdoor air should be relatively unaffected by any bias that applies to sample collection in indoor settings. The geographic regions which we studied were large and could contain localized areas with different patterns of fungal growth. Furthermore, the highest reported concentrations might be underestimates, since very high concentrations may overload a sampler. The impact of this limitation on our results, however, should have been minimized by our use of medians in most analyses. Thus, the results of this large descriptive study provide comparative data that can be used to better interpret bioaerosol samples and to improve our understanding of the role of fungi in indoor air quality investigations.

\section{ACKNOWLEDGMENTS}

We thank MeiLin Soong-Whitehead for her help with analyzing fungal samples, our other laboratory technicians for their help with data entry, the field investigators who submitted samples for analysis, and George Barron for valuable discussions.

\section{REFERENCES}

1. Andersen, A. A. 1958. New sampler for the collection, sizing, and enumeration of viable airborne particles. J. Bacteriol. 76:471-484.

2. Beaumont, F., H. F. Kauffman, H. J. Sluiter, and K. de Vries. 1984. A volumetric-aerobiologic study of seasonal fungus prevalence inside and outside dwellings of asthmatic patients living in northeast Netherlands. Ann. Allergy 53:486-492.

3. Bush, R. K., and J. M. Portnoy. 2001. The role and abatement of fungal allergens in allergic diseases. J. Allergy Clin. Immunol. 107:430-440.

4. Centers for Disease Control and Prevention. 1999. Report of the CDC Working Group on Pulmonary Hemorrhage/Hemosiderosis. Centers for Disease Control and Prevention, Atlanta, Ga.

5. Centers for Disease Control and Prevention. 2000. Update: pulmonary hemorrhage/hemosiderosis among infants-Cleveland, Ohio, 1993-1996. Morb. Mortal. Wkly. Rep. 49:180-184.

6. Centers for Disease Control and Prevention. 1999. Reports of members of the CDC external expert panel on acute idiopathic pulmonary hemorrhage in infants: a synthesis. Centers for Disease Control and Prevention, Atlanta, Ga.

7. Croft, W. A., B. B. Jarvis, and C. S. Yatawara. 1986. Airborne outbreak of trichothecene toxicosis. Atmos. Environ. 20:549-552.

8. Dillon, H. K., P. A. Heinsohn, and J. D. Miller (ed.). 1996. Field guide for the determination of biological contaminants in environmental samples, p. 24, 57, and 58. American Industrial Hygiene Association, Fairfax, Va.

9. Epstein, C. E., and L. L. Fan. 2001. Alveolar hemorrhage syndromes: update on pulmonary hemosiderosis. J. Respir. Dis. Pediatr. 3:49-56.
10. Etzel, R. A., E. Montana, W. G. Sorenson, G. J. Kullman, T. A. Allan, and D. G. Dearborn. 1998. Acute pulmonary hemorrhage in infants associated with exposure to Stachybotrys atra and other fungi. Arch. Pediatr. Adolesc. Med. 152:757-762.

11. Harrison, J., C. A. Pickering, E. B. Faragher, P. K. Austwick, S. A. Little, and L. Lawton. 1992. An investigation of the relationship between microbial and particulate indoor air pollution and the sick building syndrome. Respir. Med. 86:225-235.

12. Hirsch, R. S., and J. A. Sosman. 1976. A one-year survey of mold growth inside twelve homes. Ann. Allergy 36:30-38.

13. Hodgson, M. J., P. Morey, W.-Y. Leung, L. Morrow, D. Miller, B. B. Jarvis, H. Robbins, J. F. Halsey, and E. Storey. 1998. Building-associated pulmonary disease from exposure to Stachybotrys chartarum and Aspergillus versicolor. J. Occup. Environ. Med. 40:241-249.

14. Johanning, E., R. Biagini, D. Hull, P. Morey, B. Jarvis, and P. Landsbergis. 1996. Health and immunology study following exposure to toxigenic fungi (Stachybotrys chartarum) in a water-damaged office environment. Int. Arch. Occup. Environ. Health 68:207-218.

15. Jones, B. L., and J. T. Cookson. 1983. Natural atmospheric microbial conditions in a typical suburban area. Appl. Environ. Microbiol. 45:919-934.

16. Kodama, A. M., and R. I. McGee. 1986. Airborne microbial contaminants in indoor environments. Naturally ventilated and air-conditioned homes. Arch. Environ. Health 41:306-311.

17. Kozak, P. P., J. Gallup, L. H. Cummins, and S. A. Gillman. 1979. Factors of importance in determining the prevalence of indoor molds. Ann. Allergy 43:88-94.

18. Li, C. S., and L. Y. Hsu. 1995. Fungus allergens inside and outside the residences of atopic and control children. Arch. Environ. Health 50:38-43.

19. Macher, J. M., F. Y. Huang, and M. Flores. 1991. A two-year study of microbiological indoor air quality in a new apartment. Arch. Environ. Health 46:25-29.

20. Martin, J. P. 1950. Use of acid, rose bengal, and streptomycin in the plate method for estimating soil fungi. Soil Sci. 69:215-232.

21. Pei-Chih, W., S. Huey-Jen, and L. Chia-Yin. 2000. Characteristics of indoor and outdoor airborne fungi at suburban and urban homes in two seasons. Sci. Total Environ. 253:111-118.

22. Ren, P., T. M. Jankun, and B. P. Leaderer. 1999. Comparisons of seasonal fungal prevalence in indoor and outdoor air and in house dusts of dwellings in one Northeast American county. J. Exposure Anal. Environ. Epidemiol. 9:560-568.

23. Ren, P., T. M. Jankun, K. Belanger, M. B. Bracken, and B. P. Leaderer. 2001. The relation between fungal propagules in indoor air and home characteristics. Allergy 56:419-424.

24. Solomon, W. R. 1975. Assessing fungus prevalence in domestic interiors. J. Allergy Clin. Immunol. 56:235-242.

25. Solomon, W. R. 1976. A volumetric study of winter fungus prevalence in the air of Midwestern homes. J. Allergy Clin. Immunol. 57:46-55.

26. Verhoeff, A. P., J. H. van Wijnen, B. Brunekreef, P. Fischer, E. van ReenenHoekstra, and R. A. Samson. 1992. Presence of viable mould propagules in indoor air in relation to damp and outdoor air. Allergy (Copenhagen) 47(2 part 1):83-91.

27. Wyngaarden, J. B., L. H. Smith, and J. C. Bennett (ed.). 1992. Cecil textbook of medicine, 19th ed., p. 399 and 407. W.B. Saunders Co., Philadelphia, Pa. 